\title{
Autosomal recessive retinitis pigmentosa E150K opsin mice exhibit photoreceptor disorganization
}

\author{
Ning Zhang, ${ }^{1}$ Alexander V. Kolesnikov, ${ }^{2}$ Beata Jastrzebska, ${ }^{1}$ Debarshi Mustafi, ${ }^{1}$ Osamu Sawada, ${ }^{3}$ \\ Tadao Maeda, ${ }^{1,3}$ Christel Genoud, ${ }^{4}$ Andreas Engel, ${ }^{1}$ Vladimir J. Kefalov, ${ }^{2}$ and Krzysztof Palczewski ${ }^{1}$ \\ 1Department of Pharmacology, School of Medicine, Case Western Reserve University (CWRU), Cleveland, Ohio, USA. \\ 2Department of Ophthalmology and Visual Sciences, Washington University School of Medicine, St. Louis, Missouri, USA. ${ }^{3}$ Department of Ophthalmology, \\ School of Medicine, CWRU, Cleveland, Ohio, USA. ${ }^{4}$ Electron Microscopy Facility, Friedrich Miescher Institute, Basel, Switzerland.
}

\begin{abstract}
The pathophysiology of the $\mathrm{E} 150 \mathrm{~K}$ mutation in the rod opsin gene associated with autosomal recessive retinitis pigmentosa (arRP) has yet to be determined. We generated knock-in mice carrying a single nucleotide change in exon 2 of the rod opsin gene resulting in the E150K mutation. This novel mouse model displayed severe retinal degeneration affecting rhodopsin's stabilization of rod outer segments (ROS). Homozygous E150K (KK) mice exhibited early-onset retinal degeneration, with disorganized ROS structures, autofluorescent deposits in the subretinal space, and aberrant photoreceptor phagocytosis. Heterozygous (EK) mice displayed a delayed-onset milder retinal degeneration. Further, mutant receptors were mislocalized to the inner segments and perinuclear region. Though KK mouse rods displayed markedly decreased phototransduction, biochemical studies of the mutant rhodopsin revealed only minimally affected chromophore binding and $\mathrm{G}$ protein activation. Ablation of the chromophore by crossing $\mathrm{KK}$ mice with mice lacking the critical visual cycle protein LRAT slowed retinal degeneration, whereas blocking phototransduction by crossing KK mice with GNAT1-deficient mice slightly accelerated this process. This study highlights the importance of proper higherorder organization of rhodopsin in the native tissue and provides information about the signaling properties of this mutant rhodopsin. Additionally, these results suggest that patients heterozygous for the E150K mutation should be periodically reevaluated for delayed-onset retinal degeneration.
\end{abstract}

\section{Introduction}

Rod opsin, an apoprotein that combines with the chromophore 11-cis-retinal to form the light-sensitive visual pigment rhodop$\sin$, is critical for visual functioning of the retina $(1,2)$. Rhodopsin localizes at a 5-mM concentration in specific ciliary structures called rod outer segments (ROS) (3). This high level of protein along with the continuous renewal of ROS (4) imposes a tremendous burden on these postmitotic photoreceptor neurons, which in turn can affect the neighboring retinal pigmented epithelium (RPE). Consequently, even structurally minor mutations in the opsin gene could cause rod cell instability, aberrant signaling, or defects in intracellular trafficking that could potentially extend to other retinal layers and lead to a host of visually handicapping diseases, including retinitis pigmentosa (RP)

$\mathrm{RP}$ is the name of a heterogeneous group of hereditary retinal degenerative diseases that primarily affect rod photoreceptor cells (5) (RetNet, https://sph.uth.edu/RetNet/. RP affects over 1 million individuals worldwide and an estimated 100,000 people in the United States. Symptoms such as decreased vision under low light and loss of peripheral visual field classified as "tunnel vision" often first appear in childhood, but severe visual problems such as loss of central vision do not usually develop until early adulthood. Due to the lack of a detailed understanding of RP pathophysiology, only a few experimental therapeutic approaches have been developed (e.g., refs. 6-10), with no clinically effective treatment available to date. $\mathrm{RP}$ can be caused by mutations in more than 50 genes encoding

Conflict of interest: The authors have declared that no conflict of interest exists. Citation for this article: J Clin Invest. 2013;123(1):121-137. doi:10.1172/JCI66176 photoreceptor cell proteins with an autosomal dominant (adRP), autosomal recessive (arRP), or X-linked pattern of inheritance. More than 100 mutations have been associated with RP in the single gene that encodes rod opsin (11-13). Most of these mutations cause adRP, accounting for $30 \%-40 \%$ of the total RP cases, whereas only a few, including severe truncation of the opsin gene (14), are inherited in an autosomal recessive pattern. The c.448G >A (p.E150K) mutation in patients was the first reported missense mutation in the opsin gene associated with $\operatorname{arRP}(15,16)$, and the resulting mutant protein has since been characterized in vitro by biochemical methods $(17,18)$. Another mutation that causes arRP, G284S, is listed in RetNet, but without further biochemical characterization. Thus, it remains to be understood how missense mutations give rise to arRP in humans. Studies of RP mutations in the opsin gene can teach us about the structure and function of this key visual protein and the cell biology of one of the most metabolically active neurons, namely the rod photoreceptor cell.

The size of ROS has been shown to be proportional to the level of opsin expression. Heterozygote opsin knockout mice displayed no overt disease phenotype apart from a reduced disc diameter (19), whereas overexpression of opsin in rods increased outer segment diameters to accommodate the extra protein (20). Furthermore, rods from homozygous opsin-knockout mice failed to develop outer segments $(21,22)$. Thus, available evidence indicates that rhodopsin stabilizes the outer segment structure of rod cells, in addition to its primary function in phototransduction. There are several mechanisms potentially leading to disease in E150K patients. The E150K mutation substituting a positively charged Lys for the negatively charged Glu residue could result in disrup- 
A A bovine/human/mouse/dog
Mutations: (T) human ADRP
G human ARRP
E150K human ARRP

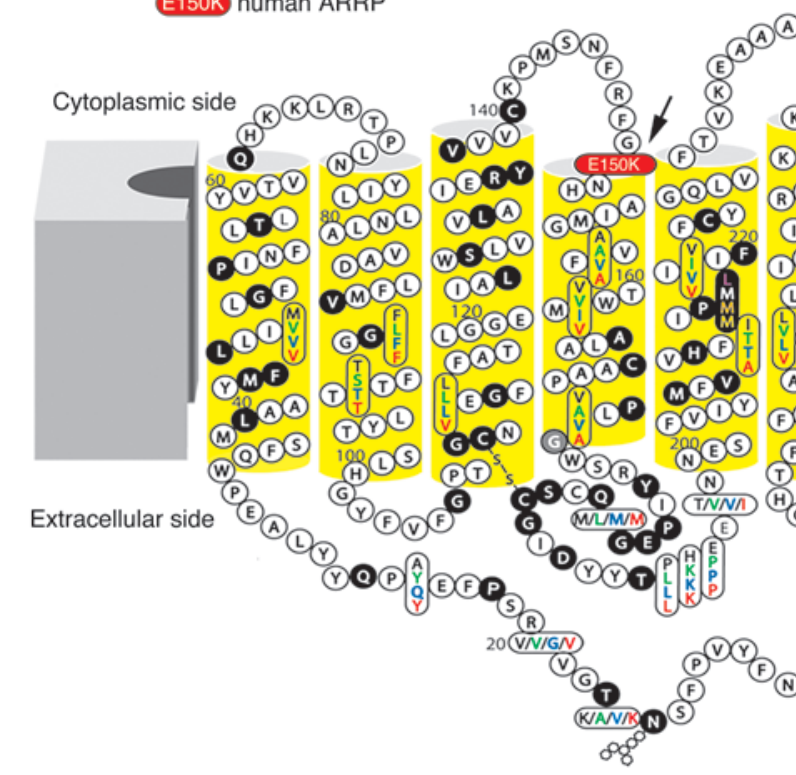

C
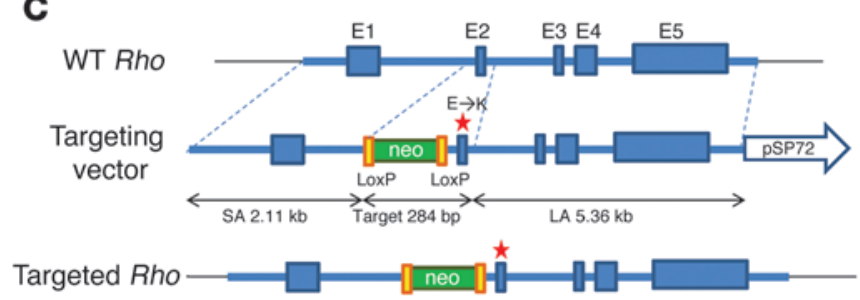

Final KI Rho

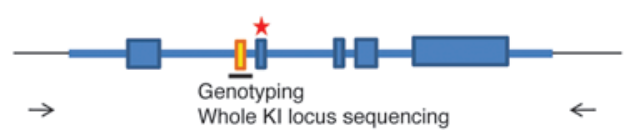

B

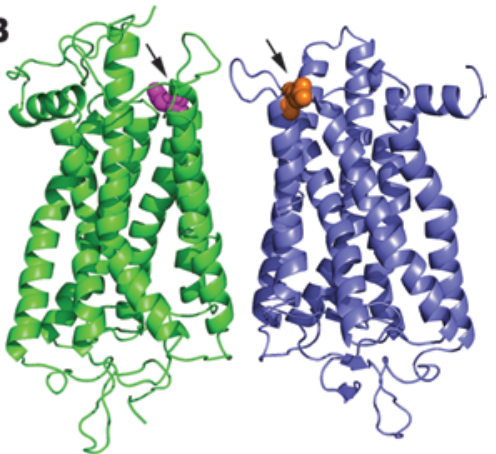

D

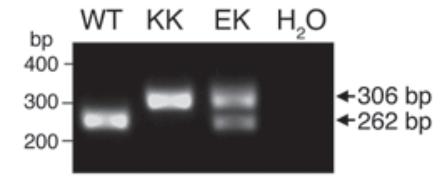

$\mathbf{E}$

Codon $\begin{array}{lllll}148 & 149 & 150 & 151 & 152\end{array}$

WT T T C GGGGA G A T C A C

E150K T T C G G GAA A G A A T C A C

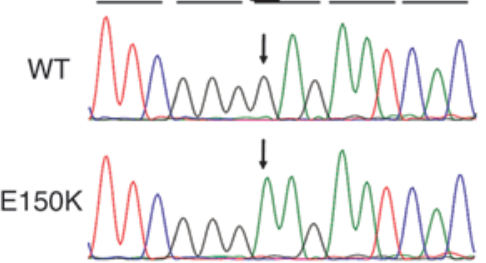

\section{Figure 1}

Rhodopsin models and targeting strategy and molecular characterization of E150K knock-in mice. (A) 2D model of rhodopsin indicate residue conservation and mutations that cause human adRP and arRP. Figure adapted with permission from Science (26). The E150K mutation is located at the interface of the cytoplasmic side with the disc membrane, close to the putative dimerization site indicated by arrows in the (B) 3D model of bovine rhodopsin. Figure adapted with permission from the Journal of Structural Biology (71). (C) E150K knock-in mice were generated by using a targeting vector containing a 2.11-kb 5' short homology arm (SA) and a $5.36 \mathrm{~kb}$ long homology arm (LA). A loxP-flanked Neo cassette was upstream of exon 2. The target 284-bp sequence region included a $G$ to A transversion at codon 150 in exon 2 (star). Codon 150 in exon 2 was changed to AAG by homologous recombination, and the flipase recognition target loxP-flanked Neo cassette was inserted before exon 2. The Neo cassette was removed by Cre-loxP recombination to generate E150K opsin knock-in mice. Whole-locus sequencing confirmed the knock-in (KI). This mouse retained a 44-bp loxP sequence in the intron between exons 1 and 2. (D) PCR primers were designed to amplify the intron where the 44-bp loxP sequence was inserted. The WT allele and E150K opsin allele produced 262- and 306-bp PCR products, respectively, whereas the negative control displayed no template contamination. (E) Chromatogram of opsin CDNA of 2 clones from one 15-day-old EK mouse retina confirmed the presence of both mutant and WT mRNAs.

tion of the higher-order organization of rhodopsin $(19,23-25)$ or cause aberrant transport of this protein to the ROS $(17,18)$. Even if the protein can properly traffic and oligomerize in rod discs, the crystal structure of rhodopsin (26) indicates that residue 150 interacts with Arg69 in the loop connecting helices I and II (C-I loop), and because almost the entire cytoplasmic surface of rhodopsin is engaged in the interaction with its $G$ protein transducin $(27,28)$, signaling by the mutant protein could also be defective. To understand the pathophysiology of arRP, one must first have a model for study that approximates the human condition.

Hypotheses regarding the pathophysiology of RP from previous data should be made with care, because results obtained with cell culture systems do not always correlate with the in vivo disease state of RP. Previous studies of adRP have shown that opsin 


\section{Table 1}

cDNA ratios of E150K opsin to WT opsin reveal no significant differences

$\begin{array}{lcc}\text { Mouse ID } & \text { No. of E150K clones } & \text { No. of WT clones } \\ 1 & 26 & 23 \\ 2 & 19 & 27 \\ 3 & 16 & 18 \\ \text { Total } & 61 & 68\end{array}$

A total of 129 opsin cDNA clones isolated from retinas of 3 P15 EK mice were sequenced and used to identify ratios of E150K and WT opsin to subtotal clone numbers in each mouse. No statistically significant differences were found among E150K and WT opsin ratios.

knock-in mice can mimic the human phenotype and reveal the pathophysiology of RP in vivo (29). Therefore, we used a gene targeting strategy to develop knock-in mice in which Glu(E) 150 is replaced by Lys(K)150. We employed multiple techniques to track gross morphological and physiological changes in the eye to show that this knock-in mouse model best mimics the genetic condition affecting E150K RP patients. A set of biochemical assays involving isolated photoreceptor membranes and purified rhodopsin from WT and mutant mice, as well as high-resolution imaging of the retinal layers, revealed that the degenerative phenotype of the latter is attributable to the structural destabilization of highly organized ROS disc membranes caused by E150K rhodopsin. Even in heterozygote mice, there is diminished visual function and structural integrity with age, warranting classification of E150K as a slowly progressing adRP rather than an arRP.

\section{Results}

$E K$ and KK mice exhibit different rates of photoreceptor degeneration. We generated E150K opsin knock-in mice by replacing the endogenous opsin gene with a mouse opsin gene carrying the E150K mutation (Figure 1, A and B). A neomycin (Neo) cassette flanked by loxP sites, first introduced into the mouse opsin gene for clonal selection, was later removed by electroporation with a Cre-expressing vector to generate E150K knock-in mice. The final knock-in allele contained the E150K mutation and one 44-bp loxP residue before exon 2 (Figure 1C). Primers flanking the loxP sequence were used for genotyping. WT mice showed a 262-bp PCR product, whereas homozygous E150K (KK) mice showed a 306-bp product; heterozygous (EK) mice had both PCR products (Figure 1D). The entire knock-in sequence was confirmed by direct sequencing of 9.2-kb PCR product amplified by primers located in the original mouse genome flanking the knock-in locus (see sequencing data in the Supplement; supplemental material available online with this article; doi:10.1172/JCI66176DS1). Sequencing cDNA from EK mice revealed transcription of both WT and E150K mRNA (Figure 1E). To determine the ratio of WT and E150K mRNA, we sequenced more than 120 cDNA clones obtained from 3 mice. Numbers of WT and E150K clones were similar, indicating that mRNA levels for the E150K and WT opsin were comparable (Table 1).

We tracked global retinal morphologies in vivo by using spectral domain optical coherence tomography (SD-OCT). Representative $3 \mathrm{D}$ reconstruction of OCT images of 2-month-old mouse retinas showed thinning of the retina indicative of photoreceptor degeneration, especially the outer nuclear layer $(\mathrm{ONL})$ in $\mathrm{KK}$ mice as compared with age-matched WT mice (Figure 2A). The ONL thickness measured from OCT images revealed the progression of retinal degeneration in EK and KK mice (Figure 2B). Retinas from KK mice rapidly degenerated, and their ONL almost disappeared by 4 months of age. Retinal detachment was also evident in some regions during OCT examination at this age (data not shown). Surprisingly, EK mice also showed retinal degeneration, but with a much slower time course, culminating in nearly complete loss of ONL by 10 months of age.

Histological analyses of retinas from KK and EK mice revealed more detailed morphological changes. At P30, the ONL consisted of 9-10 rows of nuclei in both WT and EK mice and 7-8 rows in KK mice. Retinal degeneration was rapid in KK mice, such that most of the photoreceptors had disappeared by 4 months of age. At this age, EK mice also started to lose photoreceptors, as indicated by a decline in ONL thickness to 7-8 rows of nuclei (Figure 2C). Retinal degeneration did not show regional variance. We cut retinal sections from 2-month-old mice from either the superior-inferior or nasal-temporal directions across the optic nerve head. KK mice, with only 3-4 rows of nuclei in the ONL at this age, did not show differences in those two directions (Figure 2D). Progressive degeneration could cause poor regeneration of rod visual pigment opsin in the mutant mice, leading to visual deterioration. To investigate this, we studied regeneration with an analog visual chromophore to quantify the amount of unregenerated visual pigments.

KK mice display a slight increase in free opsin accumulation. Retinal aldehydes were derivatized with hydroxylamine, and the resulting syn- and anti-oximes were extracted from 1-month-old mouse retinas. The amount of rhodopsin measured by the presence of 11-cis-retinal oximes in the retina was dramatically reduced in $\mathrm{KK}$ mice but only modestly decreased in EK mice (Figure 3A), consistent with their differing rates of photoreceptor degeneration. To examine the possibility that the observed retinal degeneration resulted from lower amounts of rhodopsin or the presence of mutant opsin, we isolated retinas from WT, EK, and KK mice and incubated them overnight in PBS alone or buffer containing 9-cis-retinal added in ethanol to prevent opsin precipitation during detergent solubilization in the next step of the procedure (30). 9-cis-retinal binds to free opsin in membranes forming stable isorhodopsin, and retinoid analysis was used to determine levels of regenerated opsin after immunoaffinity purification of rhodopsin/isorhodopsin (Figure 3). Trace amounts of 9-cis-retinal oximes contaminated with 11,13-di-cis-retinal oxime detected in the control samples resulted from thermal isomerization during sample handling (Figure 3A). Substantial increases in 9-cis-retinal oximes were detected in all regenerated retina samples compared with control samples incubated in PBS buffer alone (Figure 3A). Quantification of retinoids revealed a 4\% greater accumulation of 9-cis-retinal in retinas isolated from the KK mutant than from WT and EK mice (Figure 3B), indicating a small preferential accumulation of free opsin in KK mice. Similar results were obtained in two independent experiments. To better understand the role of E150K mutation, we purified rhodopsin from retinas of each mouse genotype to assess its folding and activation dynamics.

E150K rhodopsin is properly folded, dimerizes, and activates $G$ protein. Absorbance spectra of immunoaffinity-purified rhodopsin from WT, EK, and KK mouse eyes revealed similar profiles, indicating proper protein folding. The spectrum of rhodopsin purified from KK mutant mice exhibited a maximum absorption peak at $498 \mathrm{~nm}$ in its dark state, indicating proper formation of the Schiff base between Lys296 of the opsin and the 11-cis-retinal chromophore. 
A
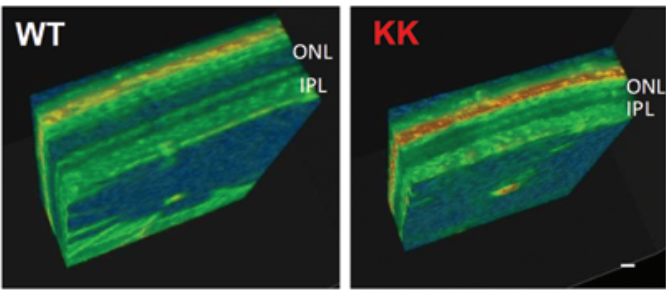

C
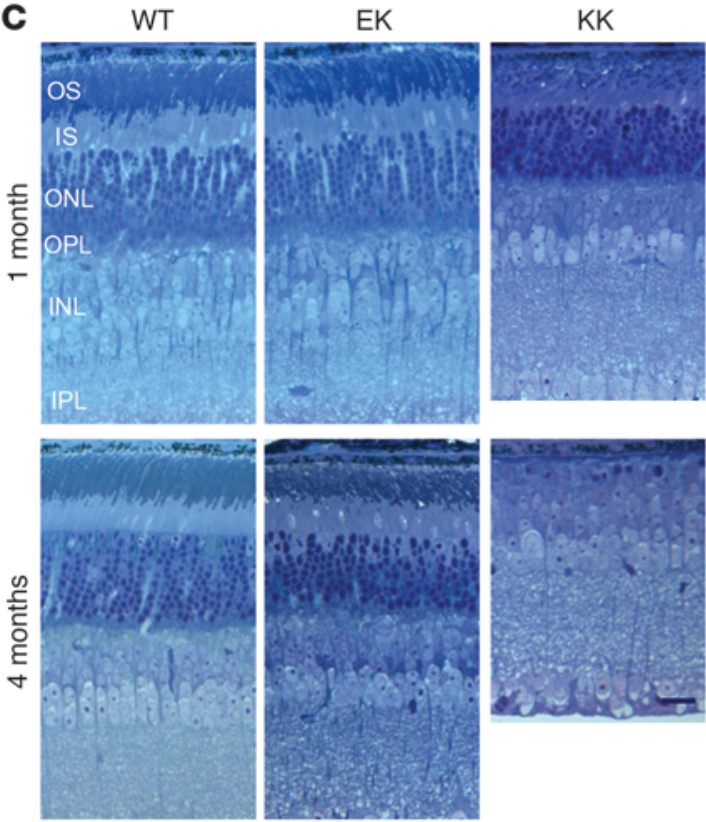

B

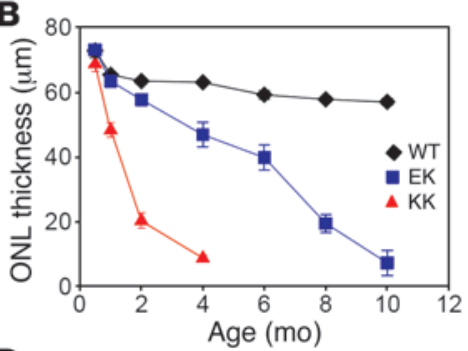

D
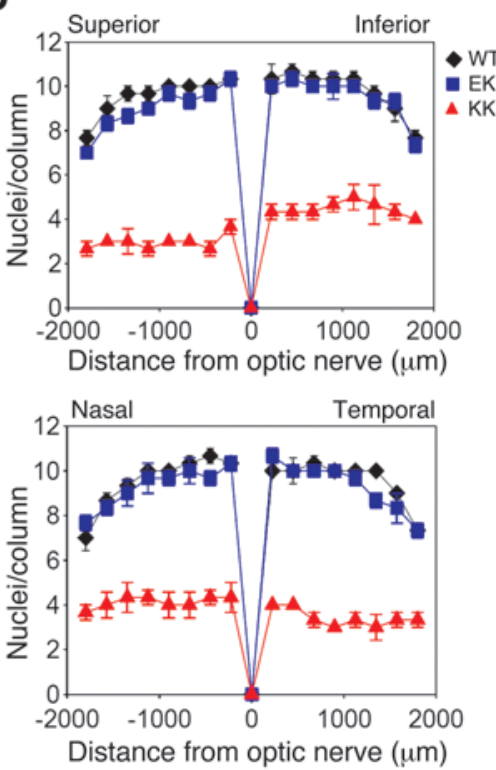

Figure 2

E150K knock-in mice undergo progressive retinal degeneration. (A) Representative 3D OCT images of 2-month-old WT and KK retinas. Scale bar: $20 \mu \mathrm{m}$. The ONL was substantially thinner in retinas of KK mice. (B) Thicknesses of the ONL measured $500 \mu \mathrm{m}$ from the optic nerve head in nasal OCT images of genetically different mice as shown at various ages $(n>3)$. KK mice evidenced photoreceptor degeneration by 1 month of age and had lost almost all their photoreceptors at the age of 4 months. (C) Plastic sections of retinas stained with toluidine blue from WT, EK, and KK mice at 1 and 4 months of age. EK retina displayed an intermediate progression of retinal degeneration indicated by modest degeneration by 4 months of age that progressed to nearly complete loss of photoreceptors by 10 months of age. (D) Numbers of nuclei per column in the superior-inferior and nasal-temporal axis of plastic sections crossing the optic nerve head in genetically different mice at 2 months of age $(n=3)$. WT and EK mouse retinas exhibited virtually identical numbers of nucleated photoreceptor cells, whereas there was substantial loss of photoreceptors in KK retina. No notable regional differences in degeneration were observed in KK retina. OPL, outer plexiform layer; INL, inner nuclear layer; IPL, inner plexiform layer.

Moreover, the KK rhodopsin spectra were similar to the absorbance spectra of dark-state rhodopsin purified from WT and EK mice, as well as following light illumination and acidification (Supplemental Figure 1A). Indeed, consistent with proper folding, the rates of chromophore release tested in a Meta II decay assay were similar for WT, EK, and KK rhodopsin samples (Supplemental Figure 1B), indicating that the E150K mutation did not perturb the activation of rhodopsin. Relative fluorescence measured to determine transducin $\left(\mathrm{G}_{\mathrm{t}}\right)$ activation rates for WT, EK, and KK rhodopsin also provided similar results for these three genotypes (Supplemental Figure 1C). Interestingly, $\mathrm{G}_{\mathrm{t}}$ activation rates were elevated slightly, but significantly $(P<0.005)$, by 1.3-fold for E150K mutant rhodop$\sin$ (KK mice) and 1.1-fold for rhodopsin from EK mice relative to WT rhodopsin. Biochemical characterization thus demonstrated and B, and Supplemental Figure 3A) from anesthetized 1- and 2-month-old WT, EK, and KK mice revealed severely attenuated scotopic responses in KK mice by 2 months of age. Photopic vision was normal at this age (Figure 4, A and B), before completely disappearing by 4 months of age (Supplemental Figure 3B). In contrast, both scotopic and photopic responses appeared normal in adult EK mice at 2 months of age (Figure 4B and Supplemental Figure 3). However, consistent with the progressive rod degeneration in these animals (Figure 2B), their scotopic a-wave responses gradually declined with age compared with corresponding levels in WT mice. Scotopic b-waves of EK mice also showed progressive age-related decline, and eventually photopic $b$-waves were reduced as well (Supplemental Figure 3, B and C). The diminishing rates of scotopic and photopic vision correlated well with the differing 
A
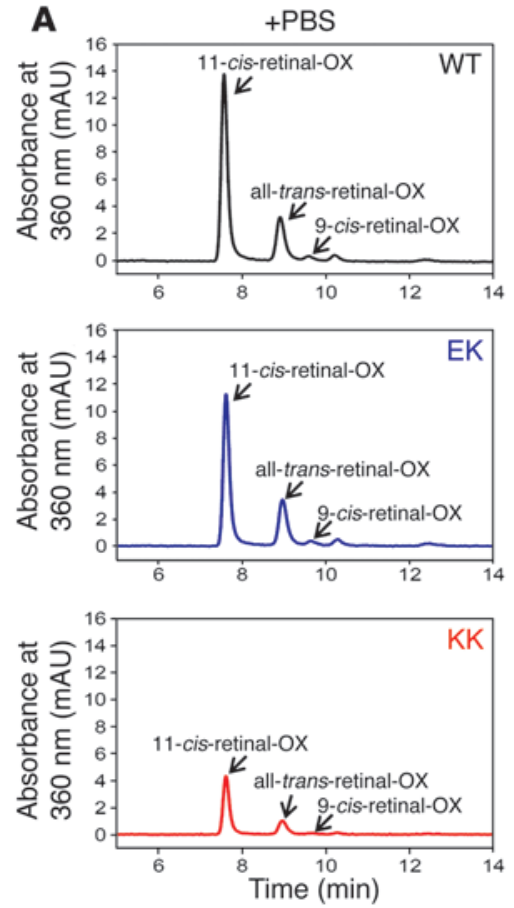
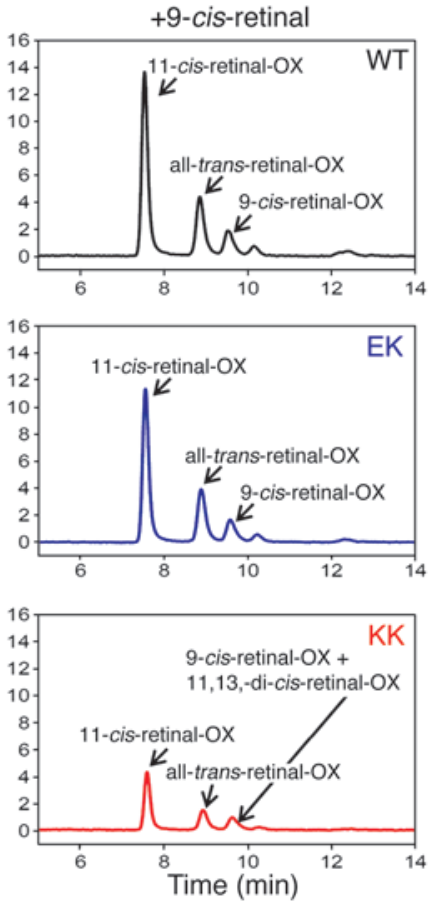

B
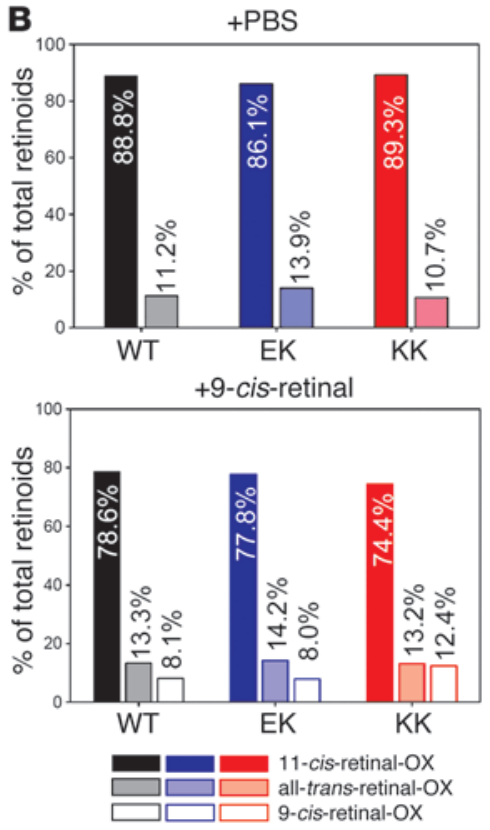

Figure 3

Regeneration of opsin with 9-cis-retinal in retinas isolated from P30 WT, EK, and KK mice. (A) Isomeric analysis of retinoid oximes (OX) is shown for rhodopsin isolated from mouse retina incubated overnight with either 9-cis-retinal in PBS (right) or with PBS alone in a control experiment (left). Retinoids were identified based on their UV-visible spectra and order of elution from an HPLC column as compared with authentic standards. (B) Quantification of retinoids was achieved by correlating areas under chromatographic peaks with those generated by known amounts of synthetic standards.

time courses of rod and cone cell degeneration, which are widely reported by many RP studies to reflect secondary cone photoreceptor degeneration after rod cell death $(31,32)$.

We performed ERG recordings from isolated mouse retinas to examine rod function in mutant mice in greater detail. Transretinal ERG recordings were carried out with isolated portions of the retina, photoreceptor side up in a recording chamber, with electrodes above and below the retina. This methodology allowed us to record events elicited following drug application over a long period and was used to detect stable photoresponses from scarce photoreceptor populations. This approach allowed us to unmask the overall response generated by rods by pharmacologically blocking post-photoreceptor components of the ERG photoresponse (33). Using this strategy, we obtained families of rod flash responses recorded from WT, EK, and KK retinas from 3- to 5 week-old mice (Figure 4C). Replacing one copy of WT rhodopsin with its mutant E150K form resulted in a $21 \%$ reduction in the maximum rod response amplitude, whereas complete substitution resulted in a much more dramatic, $80 \%$ reduction (Figure 4, C and D). Consistent with our in vivo ERG results, the maximal amplitude of the rod responses declined with age, and no responses were observed in KK animals older than 6 weeks of age (data not shown). We then fitted the corresponding normalized intensity-response relationship for each genotype with the hyperbolic Naka-Rushton function (see Methods for details) to estimate their photosensitivity, determined as half-saturating light intensity, $\mathrm{I}_{1 / 2}$ (Figure 4, D and $\mathrm{E})$. Values for this parameter were essentially identical in EK compared with WT animals, $26.8 \pm 0.6$ photons $/ \mu \mathrm{m}^{2}(n=9)$ versus
$27.0 \pm 0.4$ photons $/ \mu \mathrm{m}^{2}(n=8)$, indicating normal rod sensitivity in EK mice. Surprisingly, despite the severe degeneration of KK rods, their normalized sensitivity was only slightly reduced, as their $\mathrm{I}_{1 / 2}$ increased by only $13 \%$, to $31.0 \pm 0.6$ photons $/ \mu \mathrm{m}^{2}(n=9)$. This result supports the possibility that rod phototransduction was largely unaffected by the E150K rhodopsin mutation. The predominant fraction of chromophore-bound E150K opsin was confirmed electrophysiologically. Treatment of dark-adapted KK retinas with 11-cis-retinal did not increase their sensitivity relative to that of control KK retinas (Figure 4D). Thus, the level of free opsin in their rods, if any, was too low to produce detectable desensitization. For more refined analysis of phototransduction, we then turned to single-cell recordings.

Phototransduction efficiency is preserved in KK mice. To discriminate between photoreceptor degeneration and phototransduction deficiency, we carried out single-cell suction electrode recordings from rods of mice with differing genetic backgrounds to obtain families of flash responses from WT, EK, and KK retinas at 3-5 month of age and analyze their properties (Figure 5A). The maximal response amplitude reflecting the size of the dark current, $\mathrm{I}_{\text {dark, }}$, was reduced by $10 \%$ in EK rods and by $41 \%$ in KK rods on average relative to WT controls (Figure 5B and Table 2). Thus, the reduction in the number of functional rods and the decline in the dark current of individual cells contributed about equally to the $20 \%$ and $80 \%$ reduction in maximal transretinal rod ERG rod response observed in EK and $\mathrm{KK}$ retinas, respectively. In addition, the intensity-response curve of $\mathrm{KK}$ rods appeared somewhat shallower (Figure 5C), though the mechanism producing this 
A
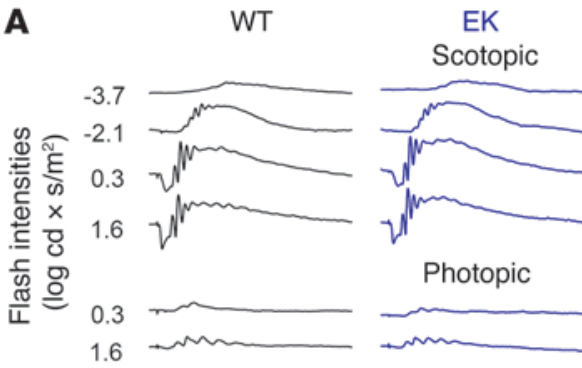

B
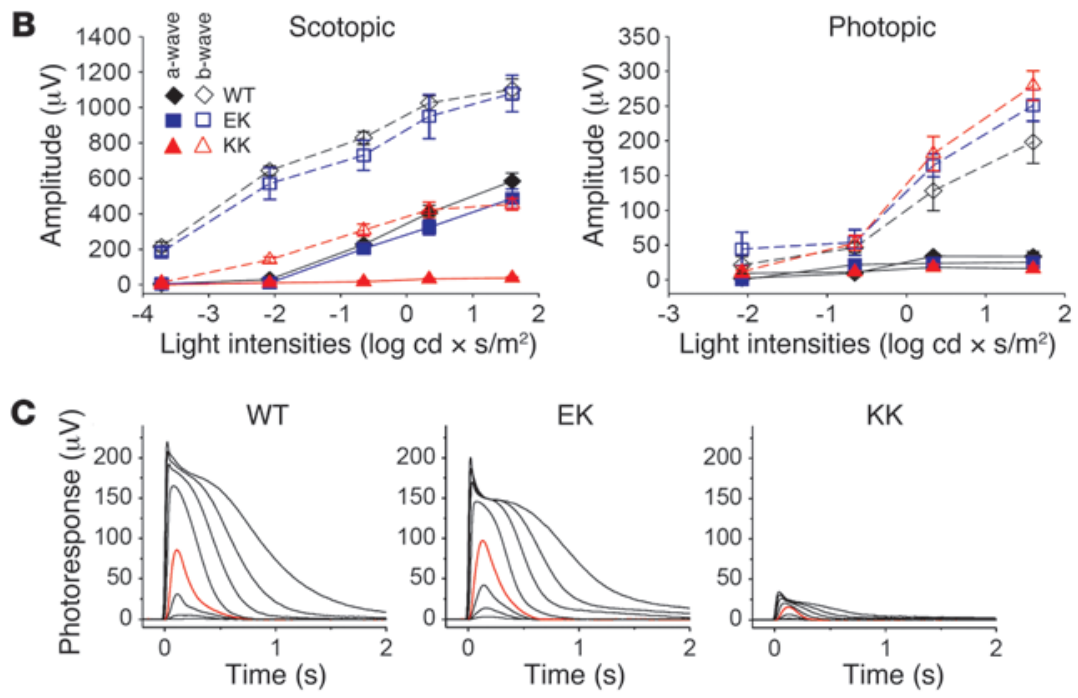

D

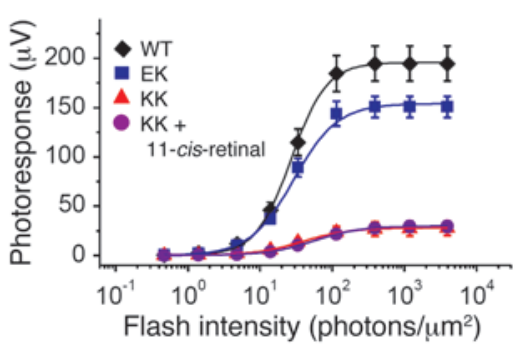

E

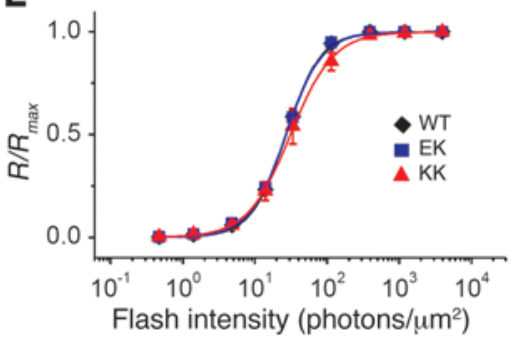

\section{Figure 4}

In vivo ERG responses and transretinal rod ERG responses of WT, EK, and KK mice. (A) Representative full-field scotopic and photopic ERG responses of anesthetized WT, EK, and KK mice at 2 months of age show reduced scotopic responses, while photopic responses were still normal in KK as compared with WT mice. Scotopic and photopic responses were normal in EK mice. (B) Amplitudes of rod photoreceptor cell-evoked scotopic (left) $\mathrm{a}$ - and b-waves were reduced in KK mice, whereas cone photoreceptor cell-dependent photopic (right) a- and b-wave amplitudes were normal at 2 months of age $(n>4)$. Amplitudes of a- and b-waves under both scotopic and photopic conditions remained unchanged in EK mice. (C) Transretinal rod ERG responses from representative WT, EK, and KK retinas. Flash strengths were increased stepwise from 1.4 to 3,920 photons $/ \mu m^{2}$, by steps of $0.5 \mathrm{log}$ units each (505 nm light). Red traces of WT, EK, and $\mathrm{KK}$ data represent responses to an identical light intensity (33 photons $/ \mu^{2}{ }^{2}$ ) for comparison. In these 3 retinas, maximum responses were 185, 150, and $23 \mu \mathrm{V}$, respectively. Absolute (D) and normalized (E) transretinal rod ERG response amplitudes as a function of flash strength are shown. Points were fitted with Naka-Rushton hyperbolic functions for WT $(n=8)$, EK $(n=9)$, and KK $(n=9)$ mice. The intensity-response relation is shown (in purple) for KK retinas treated with $130 \mu \mathrm{M} 11$-cis-retinal (1 hour, at room temperature) prior to recording $(n=4)$. effect was not investigated. Notably, the normalized rod sensitivity estimated from the amplitude of dim flash responses divided by their flash strength and normalized to the corresponding dark current was comparable in WT, EK, and KK rods (Table 2). Consistent with the normal sensitivity of EK rods, their normalized intensity-response curves overlapped completely with those of WT rods (Figure $5 \mathrm{C}$ ), and their corresponding $\mathrm{I}_{1 / 2}$ values were also similar (Table 2). The shallower intensity-response curve of KK rods resulted in a slightly higher $\mathrm{I}_{1 / 2}$ value (Table 2 ), although the dim flash section of the curve was identical to those of WT and EK rods (Figure 5C). Together, these results demonstrate that, despite its association with severe retinal degeneration, the mutant E150K rhodopsin was fully functional and could activate the rod phototransduction cascade as efficiently as WT rhodopsin.

We also examined the response kinetics of mutant rods. For all three mouse lines, we compared the averaged (cell population) means and normalized these to their corresponding dark-current $\operatorname{dim}$ flash responses. These responses were to flashes that suppressed approximately 0.2 of the total rod dark current and fell within the linear range of the rod intensity-response relationship. Notably, the activation phase of the photoresponse, indicative of signal amplification during phototransduction, was unaffected by the E150K mutation (Figure 5D). Rather, the expression of the mutant rhodopsin resulted in broadening of the peak of the dim flash response and acceleration of its shutoff. The consequent increase in the time to peak, $\mathrm{T}_{\text {peak }}$, and acceleration of the recovery time constant, $\tau_{\text {rec }}$, were especially pronounced in KK rods (Figure $5 \mathrm{D}$ and Table 2). Finally, the dominant time constant of recovery from saturating flashes, $\tau_{\mathrm{D}}$, was also accelerated (Figure $5 \mathrm{E}$ and Table 2), suggesting accelerated transducin/phosphodiesterase (PDE) inactivation in the mutant rods (34).

E150K rhodopsin mutant has reduced thermal stability. To determine how the E150K mutation affects the thermal stability of rhodopsin, we measured time-dependent denaturation of rhodopsin from WT, EK, and KK mice in isolated retinas. After 5.5 hours of incubation at $60^{\circ} \mathrm{C}$, E150K mutant rhodopsin lost approximately $81 \%$ of the chromophore, whereas rhodopsin from both WT and EK retinas lost approximately $68 \%$ of the chromophore 

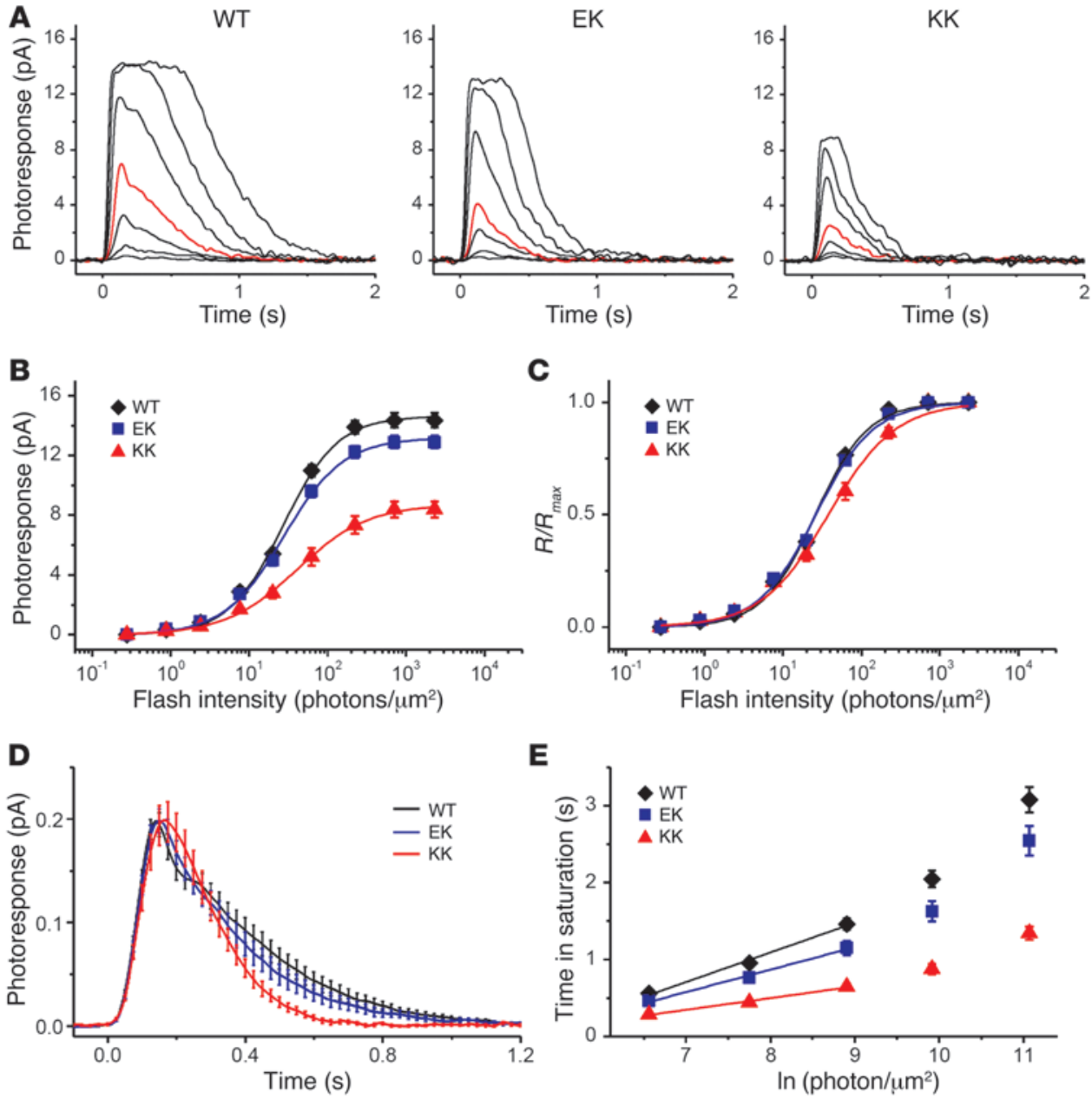

\section{Figure 5}

Single-cell suction electrode responses of WT, EK, and KK rods from 3- to 5-week-old mice. (A) Families of single-cell responses from representative WT (left), EK (middle), and KK (right) rods. Flash strengths were increased from 0.9 to 706 photons $/ \mu \mathrm{m}^{2}$, by single steps of $0.5 \mathrm{log}$ units each $(500 \mathrm{~nm}$ light). Red traces show responses to the identical light intensity $\left(20\right.$ photons $\left./ \mu \mathrm{m}^{2}\right)$ for comparison. In these 3 cells, dark currents were 14.2, 13.0, and 8.9 pA, respectively. Absolute (B) and normalized (C) single-cell response amplitudes are shown as a function of flash strength. Points were fitted with Naka-Rushton hyperbolic functions. WT $(n=19)$, EK mutant $(n=19)$, KK mutant $(n=18) l_{1 / 2}$ levels are shown in Table 2 . (D) Normalized single-cell dim flash responses (to light intensities of 7.6 photons $/ \mu \mathrm{m}^{2}$ ) from dark-adapted WT, EK, and KK opsin mutant rods. Phototransduction activation was unaffected, but broadening of the response peak and acceleration of dim flash recovery (see Table 2) were observed in KK rods, whereas EK cells displayed an intermediate phenotype. $(E) \tau_{D}$ values from a series of supersaturating flashes. Linear fits through the data yielded $\tau_{\mathrm{D}}$ values of $385 \pm 23 \mathrm{~ms}$ (WT, $\left.n=19\right), 292 \pm 24 \mathrm{~ms}(\mathrm{EK}, n=19)$, and $152 \pm 14 \mathrm{~ms}(\mathrm{KK}, n=18)$. Recovery from saturating flashes was also accelerated in mutant photoreceptor cells. Data are mean \pm SEM.

(Figure 6A), indicating that the E150K mutant was less thermally stable. Interestingly, the greatest difference in rhodopsin stability between KK and either WT or EK retinas occurred within the first 45 minutes of incubation, with further loss proceeding at a similar rate for all 3 rhodopsin samples.

Consistent with the reduced thermal stability of the E150K rhodopsin, we also observed increased dark cellular noise in our singlecell recordings from mutant rods (Figure 6B). The greater spontaneous phototransduction activity of mutant rods was revealed by comparing the power spectra of WT and mutant rods after sub- tracting the instrumental noise measured in bright, saturating light (Figure 6C). Mean variances $\left(\sigma^{2}\right)$ of the dark current increased from $0.015 \pm 0.005 \mathrm{pA}^{2}(n=16)$ for WT rods to $0.030 \pm 0.005 \mathrm{pA}^{2}$ $(n=16, P<0.05)$ and $0.043 \pm 0.005$ $\mathrm{pA}^{2}(n=16, P<0.001)$ for EK and KK rods, respectively. Thus, substituting E150K rhodopsin for its WT form increased the dark current variance 3-fold. Given the $40 \%$ reduction in dark current of $\mathrm{KK}$ rods, this translates into an 8.3-fold increase in rod spontaneous phototransduction activity. The changes in dark current might also be reflected by degenerative changes in mutant ROS. Therefore, in spite of minor variations of physiological responses, lack of a markedly dysfunctional phenotype for the E150K mutant rhodopsin suggested the pathophysiology of disease could be driven by structural factors.

KK mice display disordered photoreceptor disc structures that disrupt normal phagocytosis. Histological analysis of toluidine blue-stained retinas revealed characteristic round-shaped and denser staining of the entire nucleus (Figure 7A, arrows), typical of pyknosis observed in light-induced photoreceptor degeneration (35). Disorganized photoreceptor cell outer segments also were noted, which prompted higher-resolution studies with transmission electron microscopy (TEM). Disorganized ROS were seen in retinas of P30 KK mice and could be detected as early as P14. Compared with tightly packed discs in ROS from WT and EK mice, KK mice exhibited disordered, loose disc architecture, as well as inclusion bodies with thick enveloping membranes (Figure 7B). Digestion of shed ROS by the RPE also seemed impaired in KK mice, which, unlike WT and EK mice, had undigested loose membrane structures in their RPE cells (Figure 7C). At 4 months of age, when degeneration of EK mouse retinas was evident and retinas from KK mice had lost almost all of their photoreceptors, deposits were found in the subretinal spaces of EK mouse retinas, and pigmented deposits were also seen in the subretinal space of KK mouse retinas. Some of the deposits resembled an activated microglial cell, as a nucleus was evident and appeared to have ingested some outer segments. Moreover, KK mouse retinas were devoid of photoreceptor disc 
Table 2

Parameters of single-cell suction recordings

\begin{tabular}{|c|c|c|c|c|c|c|c|c|}
\hline & $I_{\text {dark }}(\mathrm{pA})$ & $\mathrm{T}_{\text {peak }}(\mathrm{ms})$ & $\mathrm{T}_{\text {integr }}(\mathrm{ms})$ & $S_{\mathrm{f}(\mathrm{n})}\left(\mu \mathrm{m}^{2} / \mathrm{ph}\right)$ & $\mathrm{I}_{1 / 2}\left(\mathrm{ph} / \mu \mathrm{m}^{2}\right)$ & $n\left(l_{1 / 2}\right)$ & $\tau_{\text {rec }}(\mathrm{ms})$ & $\tau_{D}(\mathrm{~ms})$ \\
\hline WT (19) & $14.3 \pm 0.5$ & $139.0 \pm 2.1$ & $338.8 \pm 21.6$ & $\begin{array}{c}2.6 \times 10^{-2} \\
\pm 1.5 \times 10^{-3}\end{array}$ & $26.5 \pm 1.4$ & $1.32 \pm 0.02$ & $217.8 \pm 12.7$ & $385.2 \pm 23.3$ \\
\hline EK (19) & $12.9 \pm 0.4^{\mathrm{A}}$ & $149.3 \pm 2.0^{B}$ & $\begin{array}{l}308.7 \pm 21.4 \\
\text { (NS) }\end{array}$ & $\begin{array}{c}2.7 \times 10^{-2} \\
\pm 1.6 \times 10^{-3}(\mathrm{NS})\end{array}$ & $\begin{array}{l}27.1 \pm 1.5 \\
\quad(N S)\end{array}$ & $1.21 \pm 0.03^{B}$ & $\begin{array}{c}187.8 \pm 15.9 \\
\text { (NS) }\end{array}$ & $292.1 \pm 24.2^{\mathrm{B}}$ \\
\hline KK (18) & $8.4 \pm 0.5^{c}$ & $166.2 \pm 5.7 \mathrm{C}$ & $250.5 \pm 10.6^{c}$ & $\begin{array}{c}2.7 \times 10^{-2} \\
\pm 2.5 \times 10^{-3}(\mathrm{NS})\end{array}$ & $45.2 \pm 6.9^{A}$ & $1.12 \pm 0.03 c$ & $116.4 \pm 7.1^{\mathrm{C}}$ & $152.3 \pm 13.7^{c}$ \\
\hline
\end{tabular}

$I_{\text {dark }}$ is the dark current measured from light-saturated responses; time to peak $\left(T_{\text {peak }}\right)$ andintegration time ( $\left.T_{\text {integr }}\right)$ refer to responses with amplitudes of approximately $0.2 \mathrm{I}_{\text {dark }}$ that fell within the linear range; $\mathrm{S}_{\mathrm{f}(\mathrm{n})}$ is the normalized dim flash fractional sensitivity (amplitude of dim flash response divided by flash strength and then normalized for the amplitude of the saturating response); $I_{1 / 2}$ represents the half-saturating light intensity; $n$ ( $\left.I_{1 / 2}\right)$ is the Hill coefficient in the Naka-Rushton equation; $\tau_{\text {rec }}$ is the time constant representing the single-exponential decay of that dim flash response recovery phase; $\tau_{D}$ is the dominant time constant of recovery after supersaturating flashes determined from the linear fit to time in a saturation versus intensity semilog plot. Values shown are mean \pm SEM. ${ }^{A} P<0.05,{ }^{B} P<0.01,{ }^{C} P<0.001$, compared with WT values.

structures at this age (Figure 7D). These structural defects could have profound effects not only on the photoreceptors, but also on the RPE layer, which must clear these aberrant discs by phagocytosis. Therefore, to understand the effect of E150K mutant rhodopsin, we imaged the photoreceptor-RPE interface with serial block face scanning electron microscopy (SBF-SEM) of P14 KK mice $(36,37)$. A $15-\mu \mathrm{m}$-thick section of KK mouse retina outside of the optic nerve was sectioned $100 \mathrm{~nm}$ at a time. The resulting volume is shown in Figure 8A, with abnormal photoreceptor inclusions seen throughout the RPE layer highlighted in the $3 \mathrm{D}$ reconstruction of the RPE layer. This illustrates that this phenomenon seen in single TEM sections is a global phenotype of the E150K retina. Moreover, examination of the photoreceptors and the RPE cell they contact reveals the aberrant photoreceptor morphology that could give rise to pathological disc structures that must be processed by the RPE (Figure 8B). Structural deformities induced by the $\mathrm{E} 150 \mathrm{~K}$ mutation leading to abnormal disc processing and subretinal deposits could cause profound changes in retinal homoeostasis that lead to immune activation. Therefore, we investigated retinal pathology in greater detail to determine whether immune activation could play a role in disease progression.

$K K$ mice display rhodopsin mislocalization and retinal immune activation. Immunohistochemical staining of rod cells labeled with 1D4 antibody (38) and nuclear layers labeled with DAPI revealed that by $\mathrm{P} 30$, the ROS and ONL of KK mice were shorter than those of WT and EK mice (Figure 2, Figure 9A, and Supplemental Figure 4). Though rhodopsin normally localizes in ROS, the mutant protein mislocalized in part to the inner segment and perinuclear region in KK mice (Figure 9A), an observation consistent with findings in cultured HEK293 cells (18). The decline in the photoreceptor population was unique to rods, as immunohistochemical staining of cone cells labeled with peanut agglutinin (PNA) (35) revealed that cone cell numbers were similar to those in retinas of WT and EK animals (Supplemental Figure 4). Both real-time PCR and immunoblotting experiments on rhodopsin in retinal samples at P14, when KK mice still had the same number of rod cells as WT mice, revealed that rod opsin did not change at the transcriptional level but instead decreased at the protein level in KK mice (Supplemental Figure 5, A and B). This indicates that the protein degradation machinery in rods was activated to eliminate mutant rhodopsin. In contrast, the amount of $G_{t} \alpha$ was not affected at the protein level in KK retina (Supplemental Figure 5B), indicating that degraded rhodopsin had no effect on other membrane-asso- ciated or signaling proteins. By P30, the rhodopsin content in KK retina was about one-third that in WT or EK retina (Supplemental Figure 5C), which quantitatively correlates with the shortening of the ROS documented in KK mice.

Using scanning laser ophthalmoscopy (SLO) with an excitation wavelength of $490 \mathrm{~nm}$ and an emission filter of 500-700 nm, we detected autofluorescent spots in the retinal fundus of 2-monthold EK and KK mice, with many more seen in the latter (Figure 9B). Such spots were not detectable in the fundus of 1-month-old KK mice (data not shown). Because the observation of autofluorescent spots by SLO can be attributable to possible inflammatory activation in retinas of EK and KK mice $(39,40)$, we used immunohistochemistry to label and identify activated Müller cells with glial fibrillary acidic protein (GFAP) $(41,42)$ and macrophage/ microglia cells with ionized $\mathrm{Ca}^{2+}$-binding adaptor molecule 1 (Iba1) (43). We found massive Müller cell activation in 1-monthold KK mouse retina, as evidenced by increased GFAP staining (Figure 9C). In the WT retina, Iba1 labeling was seen only in the inner retina, but in KK retina, activated macrophages/microglia were also found in the outer segment/inner segment (OS/IS) of photoreceptor cells (Figure 9D), indicative of immune cell migration into the subretinal space.

Genetic manipulation of key visual cycle and phototransduction proteins bighlights that the structural defect of KK mice leads to primary degeneration. Mice with a knockout of the visual cycle enzyme lecithinretinol acyltransferase (Lrat) lack 11-cis-retinal for visual pigment regeneration, and rod cells of these mice undergo a slow degeneration, usually after 2 months of age $(44,45)$. We investigated photoreceptor cell survival in KK mice after genetic ablation of 11-cisretinal by cross-breeding them with $\mathrm{Lrat}^{-1-}$ mice. In contrast to $\mathrm{KK}$ mice, retinal degeneration was less severe in $\mathrm{KKLrat}^{-1}$ mice, as manifested by a 2-fold increase in ONL thickness and rod photoreceptor length at 2 months of age (Figure 10, A and B). $\mathrm{KKLrat}^{-}$ retinas still underwent degeneration, with significantly decreased ONL thickness compared with that of age-matched $\mathrm{Lrat}^{-1-}$ mice. A mouse with a knockout of the transducin $\alpha$ subunit (Gnat1), a key component for visual phototransduction in rods, was then used to investigate the role of phototransduction in KK rod degeneration (46). By cross-breeding Gnat $1^{-/-}$with KK mice, we found that photoreceptors degenerated faster in KK mice lacking phototransduction. The ONL thickness was $33.0 \pm 2.0 \mu \mathrm{m}$ in $\mathrm{KKGnat}^{-/-}$and $43.3 \pm 1.3 \mu \mathrm{m}$ in KK retina based on OCT images at 1 month of age. But the ONL thickness of Gnat $1^{-/-}$mice was $58.8 \pm 1.6 \mu \mathrm{m}$, 
A

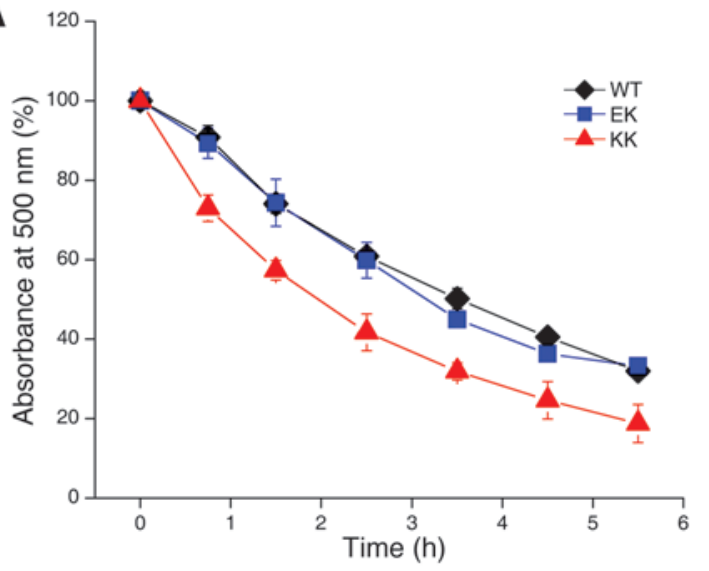

B

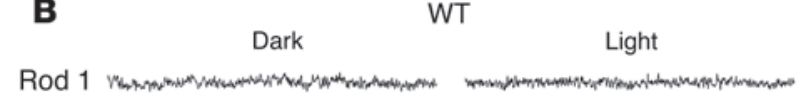

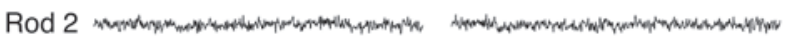

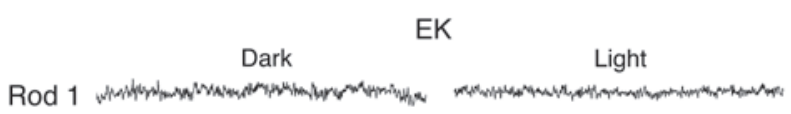

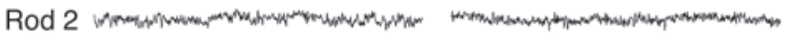
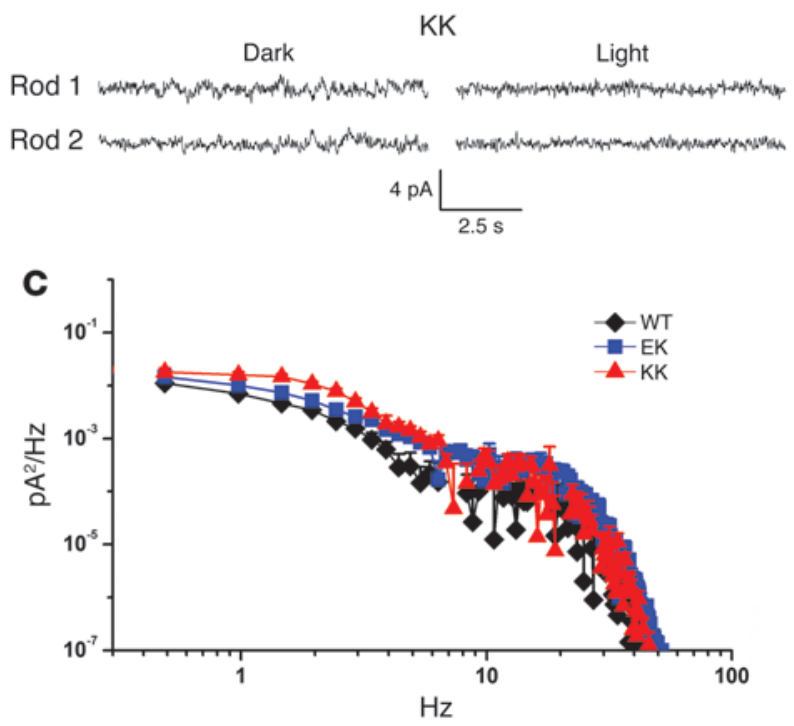

comparable to that of WT at this age (Figure 10, C and D). Taken together, these results indicate that apo-E150K opsin is toxic to rod cells, albeit less toxic than E150K rhodopsin, and the lack of phototransduction somehow accelerates retinal degeneration in these mutant mice. Most importantly, lack of a marked phenotypic change resulting from these genetic manipulations indicates that although the visual cycle and phototransduction can play a role in the retinal degeneration of $\mathrm{E} 150 \mathrm{~K}$ mice, the overriding force driving this degenerative phenotype is likely to be the structural destabilization caused by mutated $\mathrm{E} 150 \mathrm{~K}$ rhodopsin.

\section{Discussion}

The discovery of genetic disease mutations in humans is accelerating in this age of high-throughput sequencing of both exons

\section{Figure 6}

Thermal stability of rhodopsin in retinas isolated from P30 WT, EK and KK mice. (A) UV-visible absorbance spectra of rhodopsin in retinal membrane suspensions measured at different time points after incubation at $60^{\circ} \mathrm{C}(0$ minutes, 45 minutes, and $1.5,2.5,3.5,4.5$, and 5.5 hours). Thermal decay of rhodopsin was determined by plotting the results based on $100 \%$ absorption at time 0 . Error bars represent SD values estimated from 3 independent experiments. (B) Representative current recordings from two sets of WT, EK, and KK rods in the dark and in saturating light that closed all cGMP-gated channels. (C) Difference power spectra (dark-light) reveal marked increases in cellular dark noise in the $0.5-$ to $20-\mathrm{Hz}$ frequency range in $\mathrm{KK}$ mice. Data are mean \pm SEM.

and whole genomes (47). However, the proper classification of these diseases as progressive or stationary, autosomal dominant or autosomal recessive, and their resulting treatments require the study of large cohorts of patients or appropriate animal models that mimic the human condition. To this end, we generated E150K opsin knock-in mice by replacing the endogenous opsin gene with a mouse opsin gene carrying the E150K mutation to study the pathophysiology of the first missense mutation associated with arRP. Retinas of KK transgenic mice failed to develop properly, and the ensuing retinal degeneration was rapid; almost all these photoreceptor cells had degenerated by 4 months of age. Meanwhile, EK mice exhibited only a $20 \%$ decline in ONL length by 4 months of age, and photoreceptor cell degeneration did not fully progress until 10 months of age (Figure 2). The most striking phenotypic change was that even at an early age, photoreceptor outer segments were disorganized in KK mice (Figure 7). Disordered and loosened discs along with formation of inclusion bodies with thick envelopes apparently affected the RPE, where proper phagocytosis of ROS was compromised. Moreover, the mutated protein partially mislocalized to the inner segment and perinuclear regions of the retina in KK mice, possibly causing massive Müller cell activation indicative of retinal stress (Figure 9). Biochemical analyses indicated that the mutated opsin was properly folded and that chromophore binding and Meta II decay were not affected. However, rates of $G_{t}$ activation by E150K rhodopsin were slightly elevated. Possibly because of the disorganized structure of ROS, the accessibility of visual chromophore was affected in mutant mice such that a fraction of opsin in dark-adapted mouse rods was increased by $4 \%$. Interestingly, genetic elimination of chromophore production appeared to stabilize rods (Figure 10A). In contrast, genetic ablation of phototransduction accelerated retinal degeneration (Figure 10B).

Several types of electrophysiological recordings were used to evaluate how the E150K rhodopsin mutation affects visual function of knock-in mice. Scotopic ERG responses in vivo and from isolated retinas evidenced severely reduced signals in KK animals, consistent with severe retinal degeneration and disorganization of the ROS, even when photopic vision was only slightly affected. Moreover, both scotopic and photopic ERG signals declined as the degeneration progressed. But because normalized sensitivity was only slightly reduced, we believe that rod phototransduction was largely unaffected by the E150K rhodopsin mutation, an interpretation supported by single-cell response recordings (Figure 5). The lack of proper structural organization and reduced volume of ROS could accelerate transducin/PDE inactivation in mutant rods, because recovery from both dim and saturating flashes was also accelerated (Figure 5, D and E). Based on our biochemical data, 
A

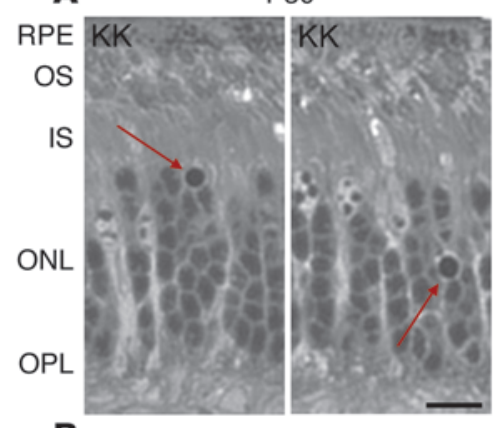

B
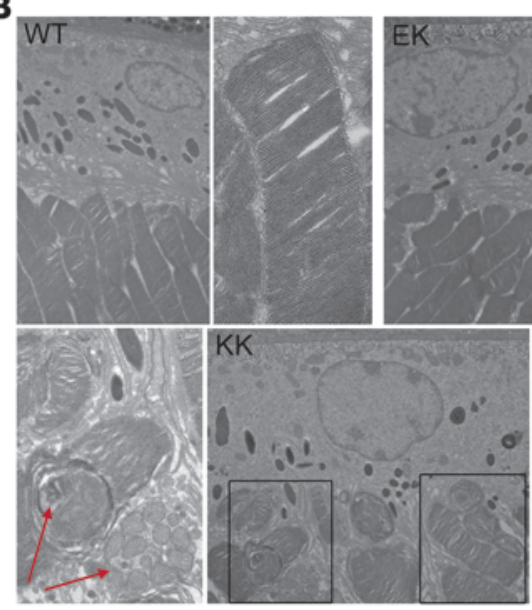

D

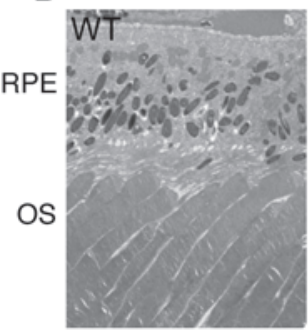

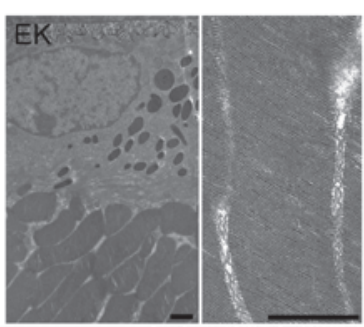

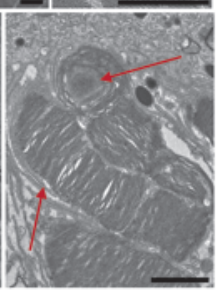

4 months
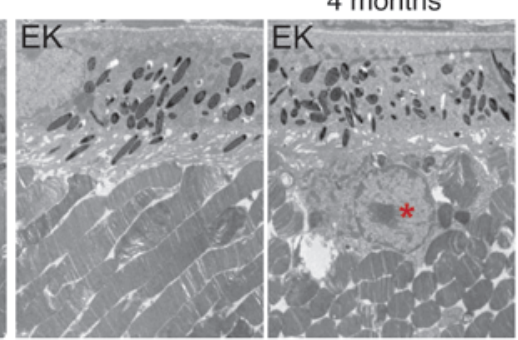

C
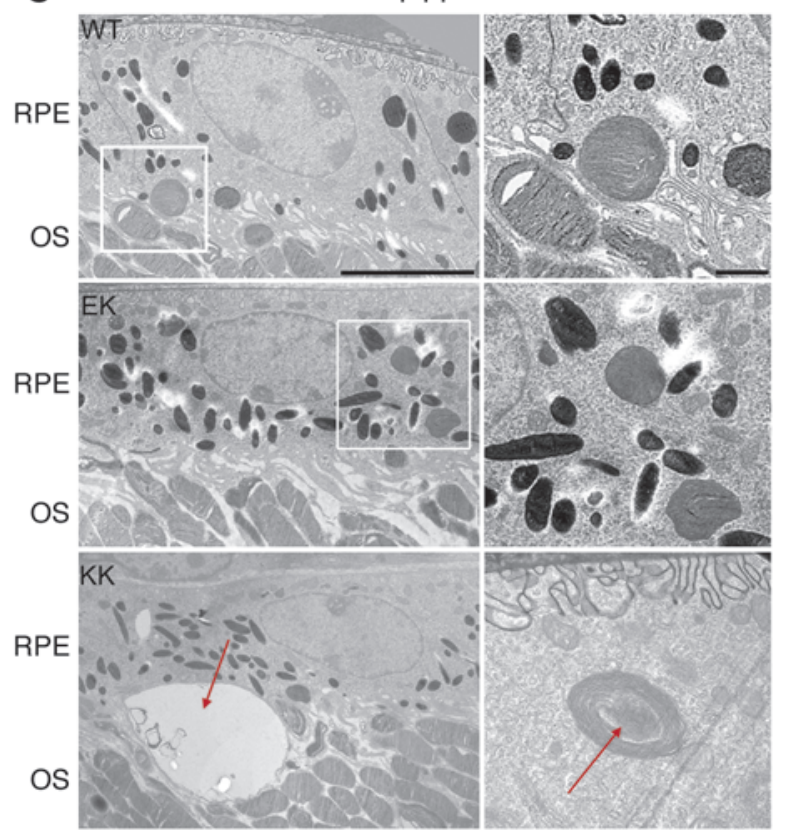

Figure 7

Photoreceptor and RPE structures in WT, EK, and KK mice. (A) Plastic sections of P30 KK mouse retinas stained with toluidine blue show disorganized photoreceptor OS with dying photoreceptor cells (arrows). Scale bar: $20 \mu \mathrm{m}$. (B) TEM images depict disordered photoreceptor OS discs in P30 KK mouse retina but not in retinas from WT or EK littermates. In WT and EK retinas, higher-magnification images reveal normal ROS architecture, whereas in the KK retina, there is severe ROS disorganization characterized by ROS with loosened and irregular shaped discs together with inclusions (arrows). Scale bars: $1 \mu \mathrm{m}$. (C) Phagosomes in P14 WT, EK, and KK RPE. Normal phagosomes were observed in P14 WT and EK mouse RPE (boxes with dashed lines in the upper two rows; scale bar: $4 \mu \mathrm{m}$ ). Augmented phagosome images are shown in right panels. Scale bar, 1 um. P14 KK mouse retinas display severe RPE pathology with undigested phagocytized discs (arrows, bottom panels) and even ingested discs show abnormal processing. (D) TEM images of retinas from 4-month-old WT, EK, and KK mice. Compared with WT retinas, EK retinas exhibit largely normal-appearing discs in most regions of the outer segment, with just a few abnormal deposits (*) in the subretinal space. KK mouse retinas completely lacked photoreceptor disc structures at this age (\&) but pigmented deposits (\#) are seen in their subretinal space. Scale bar: $5 \mu \mathrm{m}$. IS, photoreceptor inner segment.

the E150K mutant was less thermally stable, resulting in increased dark cellular noise in vivo (Figure 6) and an estimated 8.3-fold increase in rod spontaneous phototransduction activity.

Four major conclusions can be derived from the above evaluations of retinal structure and function in KK and EK mice. The first involves the disease classification of EK mutant mice, in which retinal pathology and functional decline progressed with age. This is reminiscent of fundus albipunctatus caused by muta- tions in the RDH5 gene and Oguchi disease involving mutations in arrestin and rhodopsin kinase that initially were considered stationary diseases in their homozygous forms. However, with better imaging and physiological measurements, both these diseases were found to be slowly progressive in terms of retinal degeneration and visual dysfunction because they emanated from mutations encoding key proteins of the visual cycle and phototransduction (48-50). These results along with the current study 


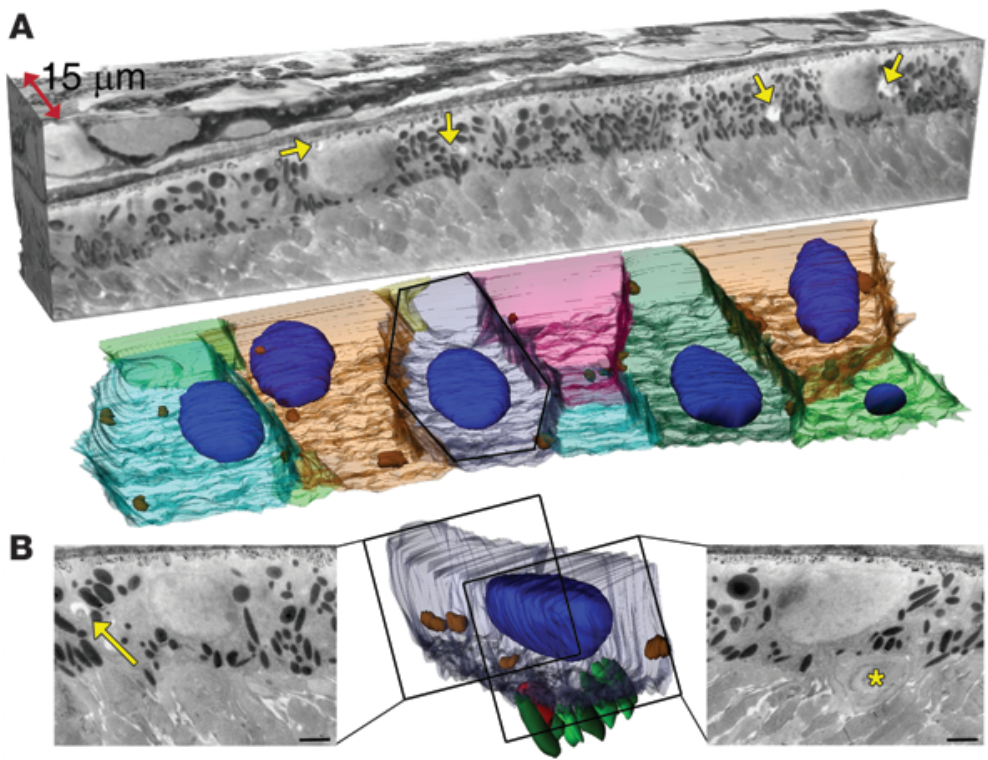

\section{Figure 8}

SBF-SEM highlights global pathological effects of the E150K mutation on photoreceptors and the RPE of the P14 KK retina. (A) SBF-SEM was carried out involving 100-nm serial sections of a $15-\mu \mathrm{m}$-deep volume of the KK retina. A $3 \mathrm{D}$ representation of the retina (abnormal disc inclusions in the RPE are indicated by yellow arrows) is shown in the upper part, with resulting reconstructions of the RPE cells depicted in different colors and abnormal disc inclusions inside the cell denoted by brown-filled volumes shown in the lower part. The center RPE cell has a characteristic hexagonal shape shown in more detail in $\mathbf{B}$, where different areas of that reconstructed RPE cell (gray, nucleus in blue) highlight representative abnormal disc inclusions indicated in the raw SEM image by yellow arrow. Abnormal photoreceptor packing (photoreceptors in green with the abnormal 1 colored red) is also seen in the raw SEM image with the abnormal photoreceptor indicated by a yellow asterisk. Scale bars: $1 \mu \mathrm{m}$. demonstrate that E150K retinopathy could similarly be properly classified as slowly progressing adRP. Thus, patients heterozygous for the E150K mutation should be encouraged to have their retinal structure and function periodically reevaluated and treatment options appropriately adjusted when they become available.

Second, these E150K opsin mutant mice reveal much about the structure and organization of the ROS. Rhodopsin is essential for ROS formation; its lack does not allow formation of ROS from embryonic rod cells $(21,22)$. Increased or decreased expression of rhodopsin produces altered ROS sizes proportional to the amount of rhodopsin synthesized $(19,20)$. Moreover, disorganization of ROS in mice with a positively charged residue in the E150K mutant contributes to disruption of the previously proposed higher-order organization of rhodopsin $(19,23-25)$. This interpretation is compatible with results indicating that lack of a sufficient amount of rhodopsin due to aberrant transport would affect the size of ROS but not their structure, and thus would not cause ROS degeneration. But the E150K rhodopsin mutant also disrupts electrostatic interactions because of the substitution of a positively charged Lys for the negatively charged Glu residue. This in turn can lead to a different oligomeric structure documented by crosslinking of rhodopsin that does not support formation of ROS. This abnormal structure is manifested by altered biochemical properties, electrophysiological responses, abnormal internal disc structure, and aberrant shedding of ROS membranes.

Third, these mice provide information about the signaling properties of this mutant rhodopsin. Previous studies in cell culture systems showed that the E150K mutation caused accumulation of positive charges on the cytoplasmic surface of rhodopsin (17, 18). Here, we demonstrate that mouse rods expressing E150K rhodopsin undergo severe and rapid retinal degeneration. As a result, the rod-driven light responses from $\mathrm{EK}$ and $\mathrm{KK}$ retinas declined by $20 \%$ and $80 \%$, respectively. Comparison of the response declines measured by transretinal and single-cell recordings indicated that a reduction in the number of functional rods and a decline in the dark current of individual rods contributed about equally to the overall reduction in rod-generated responses. Surprisingly, despite the severe degeneration of mutant rods, their normalized light sensitivity was essentially unaffected (Figures 4 and 5). Moreover, as demonstrated by the identical rising phases of their dim flash responses, amplification of the phototransduction cascade was normal in rods expressing the mutant rhodopsin (Figure 5D). Thus, despite the disruption of electrostatic interactions and the severe retinal degeneration induced by this mutation, E150K rhodopsin could effectively trigger the phototransduction cascade. This conclusion is supported by our direct measurements of transducin activation (Supplemental Figure 1C) showing that the E150K mutation not only failed to inhibit the activation of transducin but, in fact, even slightly enhanced it. Thus, we conclude that the E150K mutation does not affect the signaling properties of rhodopsin and the reduced function observed is due solely to mutant rod degeneration. Also seemingly related to ROS disorganization is the somewhat faster response shutoff observed in mutant rods (Figure 5, D and E), indicative of their accelerated transducin/PDE inactivation.

The slight increase in the apoprotein opsin fraction in independent experiments (Figure 3B) did not appear to reduce the dim flash sensitivity of mutant rods (Figure 4E). One possible explanation is that the activity of E150K opsin might be lower than that of WT opsin, thus producing a minimal activation of the phototransduction cascade in the mutant rods. However, a more likely scenario is that this increased opsin fraction is too small to reduce the sensitivity of mutant rods, as treatment of KK retinas with endogenous 11-cis-retinal failed to increase their sensitivity (Figure 4D).

A physiologically relevant change in the properties of this mutant opsin was a reduction in its thermal stability (Figure 6A). Consistent with this result, we also observed a 3-fold increase in cellular noise exhibited by mutant KK rods (Figure 6, B and C), indicating an 8.3-fold increase in rod spontaneous phototransduction activity. However, it is currently unclear what fraction of this increase was due to the increased spontaneous activation of E150K rhodopsin and what fraction, if any, was due to changes in basal phototransduction activity associated with the degenerative morphological changes in the ROS.

Finally, the E150K mouse opsin mutant displayed differences in stability after genetically induced ablation of the visual cycle 

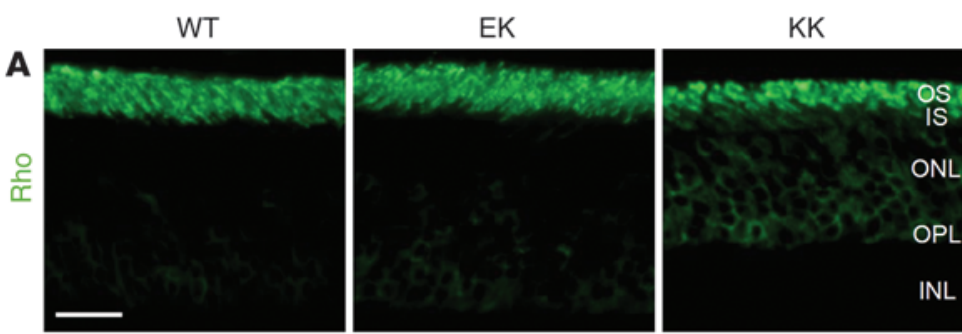

$\mathbf{B}$
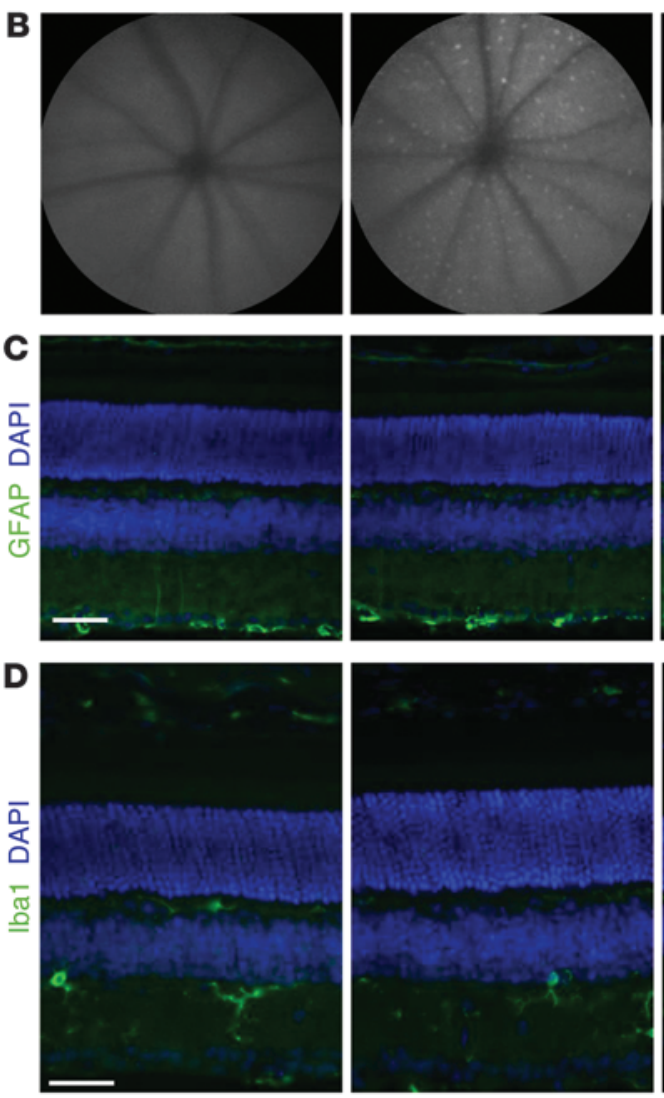
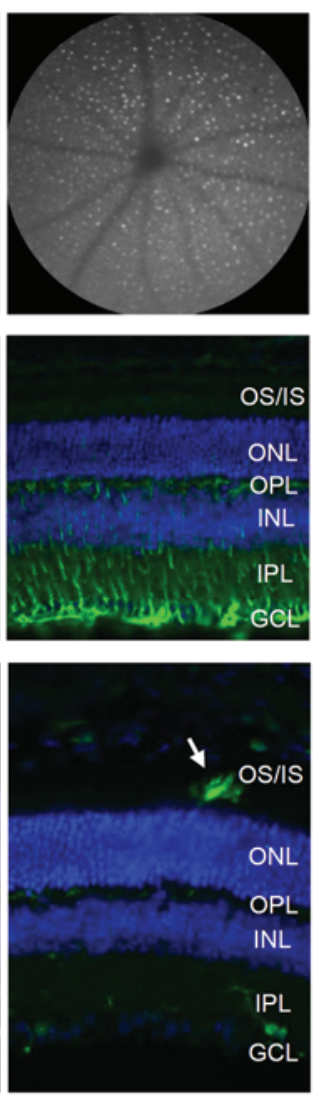

\section{Figure 9}

Rhodopsin mislocalization, fundus autofluorescent spots, and Müller/macrophage/microglial cell activation in retinas of KK mice. (A) E150K rhodopsin probed with 1D4 antibody mislocalized in part to the inner segment and perinuclear region of 1-month-old mouse retina. In contrast, rhodopsin localized normally within the ROS of WT and EK retina. (B) SLO fundus images from WT, EK, and KK mice at 2 months of age. Numerous autofluorescent spots are evenly distributed throughout the KK mouse fundus, whereas autofluorescence is barely visible in WT fundus. EK fundus exhibited a moderate fluorescent phenotype. (C) Immunohistochemistry of 1-month-old WT, EK, and KK mouse retinas with GFAP antibody that labels activated Müller cells. Massive activation of Müller cells is evident in KK but not in WT or EK retina. (D) Immunohistochemical analysis of 1-month-old WT, EK, and KK mouse retinas with lba1 antibody (green) used to mark macrophage or microglia. In WT and EK retinas, Iba1 immunoreactivity was observed only in the ganglion cell layer $(\mathrm{GCL})$ to the OPL, whereas in KK retina, Iba1 labeling also localized to the outer photoreceptor cell layer (arrows). DAPI was used to counterstain nuclei. All immunohistochemistry was done with retinas from 1-month-old mice. Scale bars: $40 \mu \mathrm{m}$. IS, photoreceptor inner segment. of phototransduction that have potential implications for the treatment of retinal diseases. We genetically eliminated the retinoid cycle, the process that regenerates the light-sensitive chromophore 11-cis-retinal $(51,52)$. In contrast to adRP-causing opsin gene mutations $\mathrm{P} 23 \mathrm{H}(29)$ and T4R $(18,53)$, the E150K mutant opsin appears more stable under such conditions, inducing a milder retinal disease phenotype than these counterparts. This could be attributed to the profound oligomerization of opsin versus rhodopsin that could preferentially benefit the E150K mutant ROS. In contrast, ablation of phototransduction accomplished by genetic removal of the $G_{t} \alpha$ (54) slightly accelerated degeneration of E150K retina. Although we do not yet understand why this occurs, a reasonable speculation favors an ion flow imbalance in a highly compromised ROS structure. Our genetic results suggest that, in contrast to other models of RP, exposure to moderate light could be beneficial. Moreover, higher expression of WT rhodopsin in E150K mutant mice with stabilization of the oligomeric rhodopsin structure could also improve ROS stability. In conclusion, this work highlights the importance of generating proper animal models of even rare variants of RP to study their pathophysiology in vivo and emphasizes that a structural abnormality (in oligomer- ization of rhodopsin resulting in abnormal assembly of the ROS) is the primary defect induced by the $\mathrm{E} 150 \mathrm{~K}$ mutation.

\section{Methods}

Animals. E150K knock-in mice used in this study were generated by inGenious Targeting Laboratories. C57BL/6J WT mice (Jackson Laboratory) were used for crossbreeding with E150K mice. Lrat-/ $(44,55)$ and Gnat1mice (54) also were employed for crossbreeding experiments. Lack of $\mathrm{rd} / \mathrm{rd}$ and $\mathrm{rd} 8$ mutations in these animals was verified by using published methods $(56,57)$. Mice were routinely maintained in a 12 -hour light $(<10$ lux)/12-hour dark cycle, with ad libitum access to food and water.

Chemicals and antibodies. 11-cis-retinal was a gift from R. Crouch (University of South Carolina School of Medicine, Columbia, South Carolina, USA), and 9-cis-retinal was purchased from Toronto Research Chemical. DSP and DSG were purchased from Thermo Scientific. MTS was purchased from Santa Cruz Biotechnology Inc.

1D4 mouse mAb was obtained from R. Molday (University of British Columbia, Victoria, British Columbia, Canada) (58) $(5 \mathrm{mg} / \mathrm{ml} ; 1: 100,000$ dilution for immunoblotting, 1:10,000 for immunohistochemistry); B6-30 mAb was a gift from P. Hargrave (University of Florida, Gainesville, Florida, USA) (59) (1 mg/ml; 1:4,000 for immunoblotting, 1:400 
A
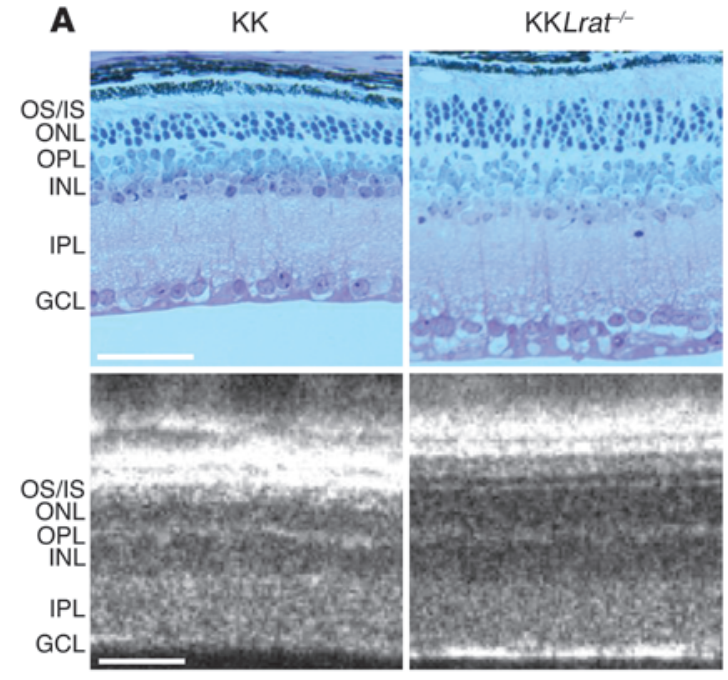

B
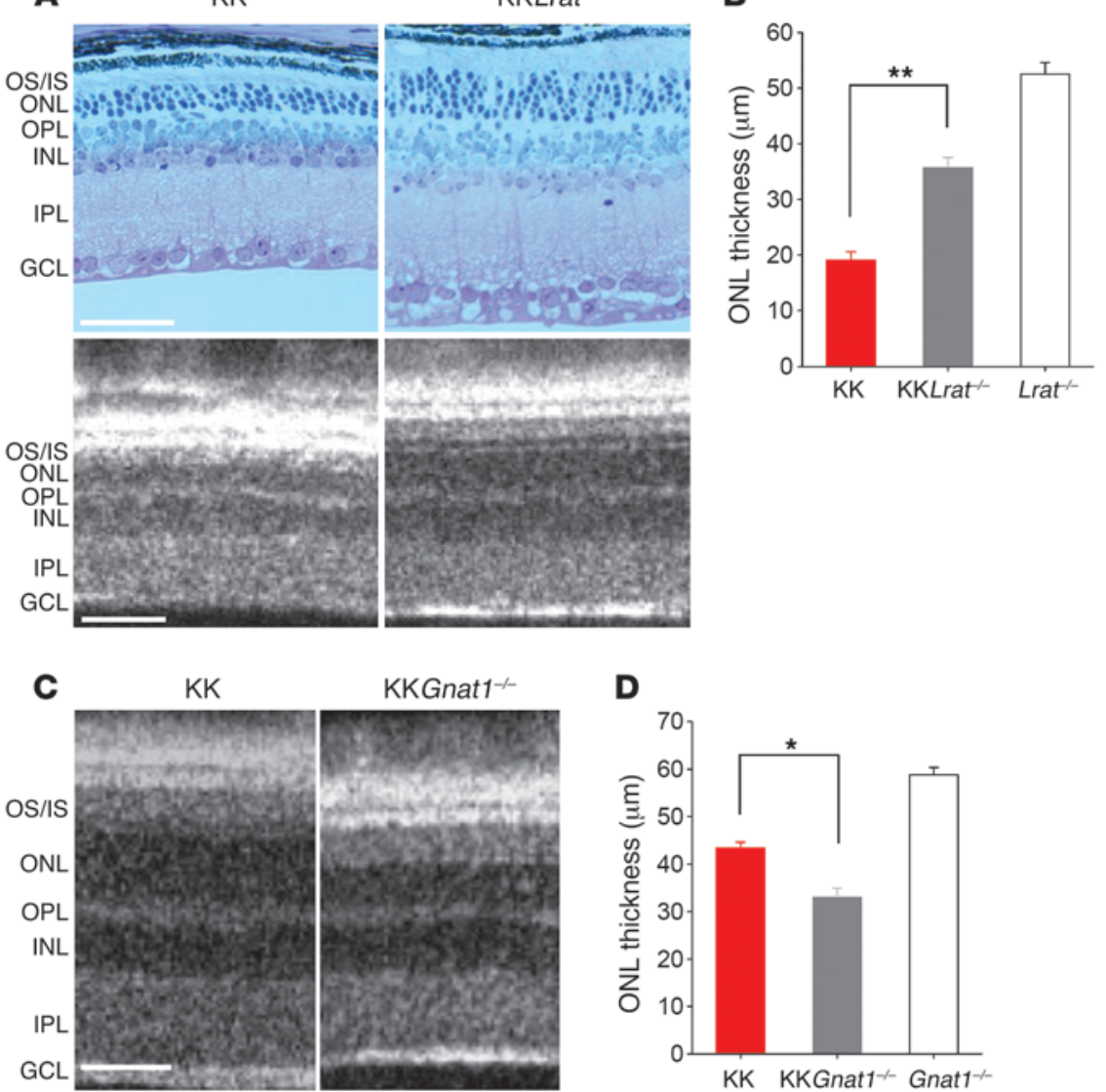

KKGnat 1--

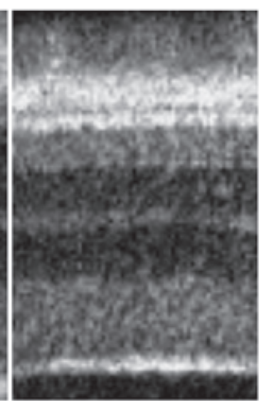

D

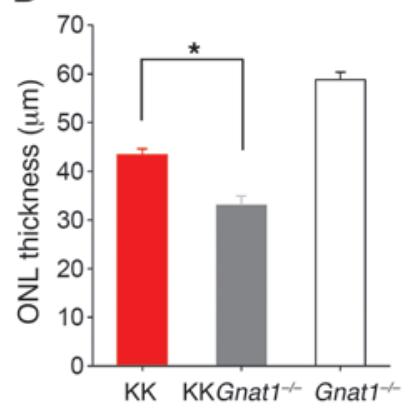

\section{Figure 10}

Effects of genetic depletion of 11-cis-retinal production or absence of rod phototransduction on retinal degeneration in KK mice. $(\mathbf{A})$ Plastic sections of retinas crossing the optic nerve head of 2-month-old KK and $\mathrm{KKLrat}^{-1}$ mice. Sections were stained with toluidine blue (upper panels). $\mathrm{KKLrat}^{--}$retina showed increased number of rows of photoreceptor cell nuclei as compared with age-matched KK retina. This finding is consistent with the increased thickness of the ONL in $\mathrm{KKLrat}^{-1}$ - retina shown in the corresponding SD-OCT images (lower panels). (B) Thickness of the ONL in KK, $\mathrm{KKLrat}^{-1}$, and $\mathrm{Lrat}^{-1}$ mice measured at 500 $\mu \mathrm{m}$ from the optic nerve head of nasal OCT images $(n>3)$. Depletion of 11-cis-retinal partially protected against retinal degeneration in KK mice. (C) SD-OCT images of retinas crossing the optic nerve head from 1-month-old KK and $\mathrm{KKGnat1}^{-/-}$mice. KKGnat1/-- retina displayed decreased thickness of ONL relative to an age-matched KK retina. (D) Thickness of the ONL in KK, KKGnat1 ${ }^{--}$, and Gnat1 ${ }^{-/-}$mice measured $500 \mu \mathrm{m}$ from the optic nerve head in nasal OCT images $(n>3)$. Absence of the $\mathrm{G}_{\mathrm{t}} \alpha$ caused greater retinal degeneration in $\mathrm{KK}$ mice. ${ }^{\star} P<0.05,{ }^{\star \star} P<0.01$. Scale bars: $20 \mu \mathrm{m}$. for immunohistochemistry); biotinylated PNA was purchased from Vector Laboratories (1:400 for immunohistochemistry); rabbit anti-GFAP polyclonal antibody (pAb) was from Dako (1:400 for immunohistochemistry); rabbit anti-Iba1 pAb was obtained from Wako (1:400 for immunohistochemistry); sc389 anti-Gat1 pAb was purchased from Santa Cruz Biotechnology Inc. (1:5,000 for immunoblotting); and AC-15 anti$\beta$-actin $\mathrm{mAb}$ was purchased from Abcam (1:5,000 for immunoblotting).

Generation of E150K knock-in mice. E150K knock-in mice were generated as follows: a $7.75-\mathrm{kb}$ region used to construct the targeting vector was first subcloned from a positively identified C57BL/6 (RP23: 88A11) BAC clone. As shown in Figure 1C, the construct was designed as follows: the short homology arm (SA) extended about $2.11 \mathrm{~kb} 5^{\prime}$ to a loxP-flanked Neo cassette inserted $183 \mathrm{bp}$ upstream of exon 2 ; the target region of $284 \mathrm{bp}$ contained the loxP-Neo cassette and exon 2 with a point mutation engineered by overlap extension PCR to introduce a G>A mutation that caused a Glu to Lys residue alteration in codon 150; and the long homology arm (LA) of $5.36 \mathrm{~kb}$ then was located $3^{\prime}$ to exon 2 . This BAC construct was subcloned into an approximately $2.4-\mathrm{kb}$ backbone vector (pSP72, Promega) containing an ampicillin selection cassette for transformation of the construct prior to electroporation. The targeting vector was linearized by NotI and then transfected by electroporation into iTL BA1 (C57BL/6 × 129/SvEv) hybrid ES cells. After selection with G418 antibiotic (Sigma-Aldrich), surviving clones were expanded for PCR analysis to identify recombinant ES clones. Clone 734, confirmed as correctly targeted, was then electroporated with a Cre-expressing vector to eliminate the Neo cassette. Electroporated clones were grown in G418-free medium. After targeted hybrid ES cells from Neo-deleted clone 181 were microinjected into C57BL/6 blastocysts, the resulting chimeric mice with a high percentage of agouti coat color were mated with WT C57BL/6 mice to generate $\mathrm{F}_{1}$ heterozygous founders. Three founders and their offspring were then identified by PCR of their genomic DNA obtained from tail biopsies with a forward primer (NDEL1, 5'-AGGCTGACATATGGACTAATGTCTGG-3') and a reverse primer (NDEL2, 5'-GCTAGGATGCAAGCTTCTGGTTTG-3') (Figure 1D).

Opsin locus sequencing. A approximately 1-cm tail snip from an $\mathrm{F}_{2}$ homozygous $\mathrm{E} 150 \mathrm{~K}$ mouse was incubated overnight at $55^{\circ} \mathrm{C}$ with $20 \mathrm{mg} / \mathrm{ml}$ proteinase $\mathrm{K}$ (Fisher Scientific) in $500 \mu \mathrm{l}$ proteinase K buffer $(50 \mathrm{mM}$ Tris, 100 $\mathrm{mM} \mathrm{NaCl}, 10 \mathrm{mM}$ EDTA, $1 \% \mathrm{SDS}$, pH 8.0). Initially, $250 \mu \mathrm{l}$ of supersaturated $\mathrm{NaCl}$ was added to each sample to solubilize proteins. Then $250 \mu \mathrm{l}$ chloroform was added as an organic layer. After shaking and centrifugation, a supernatant was obtained that contained genomic DNA. One milliliter of cold $100 \%$ ethanol was added to genomic DNA precipitated from $500 \mu \mathrm{l}$ supernatant. The precipitated DNA was rinsed twice with $70 \%$ ethanol and then dissolved in nuclease-free water. The opsin locus, including the entire targeted region, was amplified by using Takara LA Taq DNA polymerase (Takara) with the primers A4, 5'-GTCTCCATAGCCCATGGTCATCCCTC-3' and B4, 5'-AGGCAGGAGTAAAGATGACACCCCAC-3'. Resulting amplified PCR products $(8.3 \mathrm{~kb})$ were gel purified and sequenced with DNA sequencing primers at approximately 700-bp intervals.

Opsin cDNA fragment cloning. Retinas from EK mice at P15 were dissolved in $400 \mu \mathrm{l}$ TRI Reagent (Applied Biosystems). Total RNA, extracted according to the manufacturer's instructions, was dissolved in $50 \mu \mathrm{l} \mathrm{RNase-free}$ water, and contaminating genomic DNA was removed by RNase-free DNase RQ1 (Promega). cDNA was synthesized with the Power SYBR Green PCR Master Mix (Applied Biosystems) according to the manufacturer's instructions. The same amount of total RNA was processed without reverse transcriptase as a negative control. PCR was performed by using GoTaq 
Flexi DNA polymerase (Promega) with primers Rho-cDNA-F2, 5'-CTTCGGAGGATTCACCACCACCC-3' and Rho-cDNA-R2, 5'-CAATCCCGCATGAACATTGCATGCC-3'. The 308-bp predicted PCR products were not generated by negative controls involving either non-reverse-transcribed total RNA or water as templates (data not shown). After purification by a Wizard SV gel and PCR clean-up system (Promega), PCR products were ligated into pGEM-T Easy vector (Promega) and transfected into JM109 cells (Promega). Sequencing was used to determine the presence of WT and $\mathrm{E} 150 \mathrm{~K}$ opsin fragments; examples of sequence chromatograms from mouse ID L1R1 are shown in Figure 1E. To assess the ratio between E150K and WT opsin mRNA, we sequenced 129 cDNA clones from $3 \mathrm{EK}$ mice and calculated the WT to E150K opsin cDNA ratios (Table 1).

Ultra-bigh-resolution SD-OCT and SLO imaging. For all in vivo imaging, mice were anesthetized by intraperitoneal injection of a cocktail $(10 \mu \mathrm{l} / \mathrm{g}$ body weight) containing ketamine $(10 \mathrm{mg} / \mathrm{ml})$ and xylazine $(0.4 \mathrm{mg} / \mathrm{ml})$ in PBS (HyClone Laboratories). Pupils were dilated with $1 \%$ tropicamide (Bausch and Lomb). Ultra-high-resolution SD-OCT (Bioptigen) was employed for imaging (60). Four pictures acquired in the B-scan mode were used to construct each final averaged 2D SD-OCT image, and the rectangular volume scan mode was used to construct 3D images. The Heidelberg Retinal Angiograph II (Heidelberg Engineering) was employed for SLO imaging.

Immunohistochemistry. Mouse eye cups were fixed with $4 \%$ paraformaldehyde in $0.1 \mathrm{M}$ sodium phosphate buffer ( $\mathrm{pH} 7.4$ ) for 2 hours at $4^{\circ} \mathrm{C}$. Fixed tissues were dehydrated with $30 \%$ sucrose in PBS, embedded in O.C.T. sucrose mixture (1:1 O.C.T./30\% sucrose in PBS), and then frozen as described previously (61). Cryosections (12 $\mu \mathrm{m}$ thick) were cut with a cryostat-microtome (CM1850, Leica); incubated with primary antibodies 1D4, PNA, GFAP, or Iba1 (see Chemicals and antibodies for more information); and visualized with anti-mouse, goat anti-rabbit Alexa Fluor 488- or Cy3-conjugated IgGs (1:500, Jackson ImmunoResearch Laboratories Inc.) or Alexa Fluor 488-conjugated streptavidin (1:500, Invitrogen). Fluorescence was detected with a fluorescence microscope (CTR 6000, Leica). Images captured with a CCD camera (Retiga EXi Fast 1394, QImaging) were analyzed with Adobe Photoshop software.

Immunoblotting. Retinas from both eyes of a mouse were homogenized in ice-cold RIPA buffer ( $150 \mathrm{mM} \mathrm{NaCl}, 1.0 \% \mathrm{NP}-40,0.5 \%$ sodium deoxycholate, $0.1 \%$ SDS, and $50 \mathrm{mM}$ Tris, $\mathrm{pH}$ 8.0) with protease inhibitors (Sigma-Aldrich). Protein concentrations were measured with a Pierce BCA assay kit (Thermo Scientific). Protein $(15 \mu \mathrm{g})$ from each sample was transferred to immunoblot-PVDF membranes for SDS-PAGE gel electrophoresis. Primary antibodies identical to those used for immunohistochemistry were detected by incubation with goat anti-rabbit or anti-mouse secondary antibodies conjugated with horseradish peroxidase $(1: 2,000)$. Anti- $\beta$-actin (AC-15, Abcam) was employed for the loading control.

Real-time (RT)-PCR. Total RNA from mouse retinas was isolated with TRI Reagent (Applied Biosystems), and possible contaminating genomic DNA was removed by RNase-free DNase I (Promega). Total RNA $(1 \mu \mathrm{g})$ was reverse transcribed with a high-capacity cDNA reverse transcription kit (Applied Biosystems) in a total volume of $20 \mu \mathrm{l}$. Then $0.5 \%$ of this reaction mixture was used as a template for a RT-PCR reaction with Taqman Gene Expression Assays (Applied Biosystems) following the manufacturer's instructions. Mm00520345_m1 was used to probe rhodopsin, with the 18S rRNA (4319413E) probe set (Applied BioSystems) employed as an endogenous control. All real-time experiments were done with the Applied BioSystems Step-One Plus RT-PCR machine.

Histology: light and transmission electron microscopy. Mouse eyecups were first fixed overnight by immersion in 5\% glutaraldehyde/4\% paraformaldehyde, $\mathrm{pH} 7.4$, at $4^{\circ} \mathrm{C}$. Then they were washed with $0.13 \mathrm{M}$ sodium phosphate, $\mathrm{pH}$ 7.3 , and secondarily fixed with $1 \% \mathrm{OsO}_{4}$ in $0.1 \mathrm{M}$ sodium phosphate, $\mathrm{pH}$ 7.4, for 2 hours at room temperature. Eye cups subsequently were dehydrated through an ethanol series $(50 \%, 70 \%, 80 \%, 90 \%, 95 \%$, and $100 \%)$, transitioned to epoxy embedding medium with propylene oxide, and embedded for sectioning in Eponate 812. Sections for morphological study were cut at $1 \mu \mathrm{m}$ with a microtome (Leica RM2255) and stained with toluidine blue. Digital images were captured with a Leica DMI 6000 B inverted microscope. For EM studies, ultrathin sections $(70 \mathrm{~nm})$ were prepared with an ultramicrotome (Reichert-Jung Ultracut E), stained with uranyl acetate, and adsorbed onto carbon grids. A Tecnai T12 electron microscope (FEI) operating at $120 \mathrm{kV}$ or $200 \mathrm{kV}$ with a $\mathrm{LaB}_{6}$ filament was used for final imaging.

SBF-SEM, data analysis, and $3 D$ reconstructions. Blocks prepared for TEM were used for SBF-SEM. The sample was prepared and cut using a Quanta 200 (FEI) with Gatan 3View software as described previously (37). Serial sectioning was performed on the block face by cutting a 100-nm slice from the face with a diamond knife and imaging the freshly cut block from the backscattered electron signal. This process was automated to collect 200 successive images over approximately 12 hours. Imaging was performed at an accelerated voltage of $3 \mathrm{kV}$ in a low-vacuum mode ( 0.23 Torr) at 4,096by 4,096-pixel resolution, with a pixel size of $17 \mathrm{~nm}$.

After serial sectioning, images were viewed with Fiji-win32 (a version of ImageJ) and merged to form a stack. The stack was registered and aligned to account for drift that could have occurred during the experiment. The registered stack was then opened using the Reconstruct program (62), and structural elements were mapped to provide $3 \mathrm{D}$ reconstructions.

Purification of rhodopsin from mouse eyes. Eyes from two 4-week-old darkadapted WT, EK, and KK mice were collected and used immediately for rhodopsin purification or stored at $-80^{\circ} \mathrm{C}$. Eyes were homogenized with a hand-held glass homogenizer in $2 \mathrm{ml}$ buffer composed of $20 \mathrm{mM}$ Bis-Tris propane (BTP), pH 7.5, $150 \mathrm{mM} \mathrm{NaCl}, 1 \mathrm{mM}$ EDTA, and protease inhibitors. The homogenate was centrifuged at $25,000 \mathrm{~g}$ in a benchtop centrifuge for 15 minutes at $4^{\circ} \mathrm{C}$. The supernatant was discarded, and the pellet was suspended in buffer composed of $20 \mathrm{mM} \mathrm{BTP}, \mathrm{pH} 7.5,150 \mathrm{mM} \mathrm{NaCl}$, and $20 \mathrm{mM} n$-dodecyl- $\beta$-D-maltoside (DDM) (Affymetrix) and incubated at room temperature for 1 hour. The sample then was centrifuged at $100,000 \mathrm{~g}$ for 45 minutes at $4^{\circ} \mathrm{C}$. The supernatant was incubated with $0.5 \mathrm{ml}$ of 1D4 immunoaffinity resin equilibrated with buffer composed of $20 \mathrm{mM} \mathrm{BTP}$, $\mathrm{pH} 7.5,150 \mathrm{mM} \mathrm{NaCl}$, and $2 \mathrm{mM}$ DDM for 1 hour at room temperature. This resin was loaded into a column and washed with $10 \mathrm{ml}$ of the above buffer. Rhodopsin then was eluted from the column with equilibrating buffer supplemented with $800 \mu \mathrm{M} 1 \mathrm{D} 4$ peptide (TETSQVAPA). The absorbance spectrum of purified rhodopsin was obtained with a Cary50 UVvisible spectrophotometer. The concentration of rhodopsin was calculated by measuring the absorbance at $500 \mathrm{~nm}$ and using a molar extinction coefficient of $40,600 \mathrm{M}^{-1} \mathrm{~cm}^{-1}$ (63). Rhodopsin photoactivation was achieved by illuminating samples for 5 minutes with a Fiber-Lite illuminator (Dolan Jenner Industries) through a 480-520 nm band-pass filter.

Meta II decay. Meta II decay rate determinations were performed according to a tryptophan fluorescence method described previously (64). All measurements were done with $30 \mathrm{nM}$ rhodopsin dissolved in buffer consisting of $20 \mathrm{mM} \mathrm{BTP}, \mathrm{pH} 6.0,100 \mathrm{mM} \mathrm{NaCl}$, and $1 \mathrm{mM}$ DDM which favors formation of Meta II, the activated form of rhodopsin. Rhodopsin was bleached for 15 seconds with a 150-W Fiber-Lite illuminator through a 480-520 nm band-pass filter. Intrinsic tryptophan fluorescence was then immediately monitored with a PerkinElmer LS 55 fluorescence spectrophotometer at an excitation wavelength of $295 \mathrm{~nm}$ (2.5-nm slit) and an emission wavelength of $330 \mathrm{~nm}$ (5-nm slit). The temperature of the cuvette was maintained at $20^{\circ} \mathrm{C}$ with a circulating water bath. The increase in tryptophan fluorescence correlated with the release of all-trans-retinal from the binding pocket of rhodopsin. Fluorescence data were analyzed with SigmaPlot (Systat Software Inc.) by nonlinear regression fitting to an equation describing first-order reaction kinetics to obtain the time constant $\tau$. 
$G_{t}$ activation. The functionality of rhodopsin purified from mouse retinas was evaluated by a $G_{t}$ activation fluorescence assay. The molar ratio of $G_{t}$ to Rho was 10:1 at concentrations of $250 \mathrm{nM}$ and $25 \mathrm{nM}$, respectively. Protein samples were diluted in $20 \mathrm{mM}$ BTP buffer, $\mathrm{pH} 7.0$, containing $120 \mathrm{mM}$ $\mathrm{NaCl}, 2 \mathrm{mM} \mathrm{MgCl}_{2}$ and $1 \mathrm{mM} \mathrm{DDM}$ and then exposed to light for $15 \mathrm{sec}-$ onds with a Fiber-Lite covered with a band-pass wavelength filter (480-520 $\mathrm{nm}$ ). The reaction was carried out at $20^{\circ} \mathrm{C}$ in a continuously stirred cuvette. After 300 seconds of incubation, $5 \mathrm{M}$ GTP $\gamma \mathrm{S}$ was added. The intrinsic increase in fluorescence emanating from $\mathrm{G}_{\alpha t}$ was measured with a PerkinElmer LS55 luminescence spectrophotometer employing excitation and emission wavelengths of 300 and $345 \mathrm{~nm}$, respectively $(65,66)$. No changes in tryptophan fluorescence were detected in control experiments without GTP $\gamma$ S. A pseudo-first-order kinetic rate constant $(k)$ was derived from the following function: $A(t)=A_{\max }\left(1-\exp ^{-k t}\right)$, where $A_{\max }$ is the maximal $\mathrm{G}_{\alpha \mathrm{t}}$ fluorescence change and $A(t)$ is the relative fluorescence change at time $t$.

Opsin regeneration with 9-cis-retinal and retinoid analyses. Retinas were isolated from dark-adapted WT, EK, and KK mice, and each retina was incubated with $50 \mu \mathrm{M}$ 9-cis-retinal in $200 \mu \mathrm{l}$ PBS overnight in the dark on ice. The next day, the PBS buffer with excess 9-cis-retinal was discarded, and retinas were suspended in buffer composed of $20 \mathrm{mM} \mathrm{BTP}, \mathrm{pH} 7.5$, containing $150 \mathrm{mM} \mathrm{NaCl}$ and protease inhibitors and homogenized with an Eppendorf homogenizer. This solution was supplemented with $20 \mathrm{mM}$ DDM and incubated for 1 hour on ice to solubilize membranes. Samples were centrifuged at $100,000 \mathrm{~g}$ for 45 minutes. Collected supernatants were incubated with $250 \mu \mathrm{l} 1 \mathrm{D} 4$-immunoaffinity resin pre-equilibrated with $20 \mathrm{mM}$ BTP, pH 7.5, $150 \mathrm{mM} \mathrm{NaCl}$, and $2 \mathrm{mM}$ DDM for 1 hour at room temperature. Then the resin was loaded into a column and washed extensively with $25 \mathrm{ml}$ of the above buffer. To separate retinoids from rhodopsin bound to the 1D4 resin, protein was first denatured for 30 minutes with $50 \% \mathrm{CH}_{3} \mathrm{OH}$ in the presence of $40 \mathrm{mM} \mathrm{NH}_{2} \mathrm{OH}$. The resulting retinal oximes were extracted with $600 \mu \mathrm{l}$ hexane, and their isomeric content was determined by normal-phase HPLC with an Ultrasphere-Si, $5 \mu \mathrm{m}$, $4.5 \times 250 \mathrm{~mm}$ column (Beckman). Retinoids, eluted isocratically with $10 \%$ ethyl acetate in hexane at a flow rate of $2 \mathrm{ml} / \mathrm{min}$, were detected by absorption at $360 \mathrm{~nm}$. These were quantified by correlating areas under their chromatographic peaks with those generated from known amounts of synthetic standards.

Thermal stability of rhodopsin. The thermal stability of rhodopsin was measured in retinas isolated from WT, EK and KK mice. Four to 10 retinas

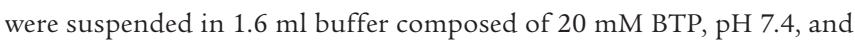
$100 \mathrm{mM} \mathrm{NaCl}$; homogenized with an Eppendorf homogenizer on ice; and then centrifuged at $1,000 \mathrm{~g}$ for 2 minutes at $4^{\circ} \mathrm{C}$ to remove unhomogenized tissue. The resulting membrane suspension was placed in an incubator at $60^{\circ} \mathrm{C}$. Then at 0 minutes, 45 minutes, 1.5 hours, 2.5 hours, 3.5 hours, 4.5 hours, and 5.5 hours, $200-\mu$ l aliquots were collected and quickly solubilized with $20 \mathrm{mM}$ DDM, and their absorbance was recorded. Resulting absorbance values at $500 \mathrm{~nm}$ were employed to create a plot of rhodopsin's thermal decay. Standard deviations were calculated from 3 sets of experimental data.

Chemical crosslinking of rhodopsin. Crosslinking reactions of rhodopsin were performed with retinas isolated from WT, EK, and KK mice. Retinas were washed twice in the crosslinking buffer composed of $100 \mathrm{mM} \mathrm{Na}_{2} \mathrm{HPO}_{4}$, $\mathrm{pH} 8.3$, containing $150 \mathrm{mM} \mathrm{NaCl}$, and then single retinas were gently homogenized in $200 \mu \mathrm{l}$ of the same buffer. Unhomogenized tissue was removed by brief centrifugation at $1,000 \mathrm{~g}$ for 2 minutes. The homobifunctional Lys residue crosslinkers DSP and DSG were solubilized in DMSO to a final concentration of $50 \mathrm{mM}$ (stock solutions) and then diluted $\times 50$ to achieve a $1-\mathrm{mM}$ concentration ( $\sim 400$ fold molar excess) in the crosslinking reaction. Crosslinking reactions were performed for 1 hour on ice and terminated by adding $1 \mathrm{M} \mathrm{Tris} / \mathrm{HCl}, \mathrm{pH} 7.5$, to a final concentration of $100 \mathrm{mM}$.
The MTS Cys residue bifunctional crosslinker was solubilized in DMSO to a final concentration of $25 \mathrm{mM}$ (stock solution) and diluted $\times 62.5$ to a final concentration of $400 \mu \mathrm{M}$ in the crosslinking reaction. This reaction was carried out for 1 hour on ice and then quenched by adding $0.5 \mathrm{M}$ $\mathrm{N}$-ethylmaleimide to a final concentration of $20 \mathrm{mM}$. In control samples, the DSP and MTS samples were treated with 100 mM DTT after crosslinking to cleave the disulfide linkages. The resulting crosslinking of rhodopsin was checked by immunoblotting with anti-rhodopsin B6-30 antibody.

Mouse ERGs. All ERG procedures were performed according to published methods (67). For single-flash recording, the duration of white-light flash stimuli (from $20 \mu$ s to $1 \mathrm{~ms}$ ) was adjusted to provide a range of illumination intensities (from -3.7 to $1.6 \log \mathrm{cd} \times \mathrm{s} / \mathrm{m}^{2}$ ). Three to 5 recordings were made at sufficient intervals between flash stimuli (from 3 seconds to 1 minute) to allow recovery from any photobleaching effects.

Transretinal ERG recordings. Three- to 5-week-old WT, EK, and KK mice were dark-adapted overnight and sacrificed by $\mathrm{CO}_{2}$ asphyxiation, and their retinas were removed under infrared illumination and stored in oxygenated aqueous $\mathrm{L} 15$ (13.6 mg/ml, pH 7.4, Sigma-Aldrich) solution containing $0.1 \% \mathrm{BSA}$ at room temperature. A single retina was mounted on filter paper with the photoreceptor side up and placed on the recording chamber with an electrode connected to the bottom of the perfusion chamber. A second electrode was placed just above the center of the retina, which was perfused with Locke's solution (112.5 mM NaCl, $3.6 \mathrm{mM} \mathrm{KCl}, 2.4 \mathrm{mM} \mathrm{MgCl}_{2}$, $1.2 \mathrm{mM} \mathrm{CaCl}_{2}, 10 \mathrm{mM}$ HEPES, pH 7.4, $20 \mathrm{mM} \mathrm{NaHCO}_{3}, 3 \mathrm{mM} \mathrm{Na}$ succinate, $0.5 \mathrm{mM}$ Na glutamate, $0.02 \mathrm{mM}$ EDTA, and $10 \mathrm{mM}$ glucose). This solution was supplemented with $2 \mathrm{mM}$ L-glutamate and $10 \mu \mathrm{M}$ DL-AP-4 to block higher-order components of the photoresponse (68); $20 \mu \mathrm{M} \mathrm{BaCl}_{2}$ to suppress the glial component (69); and MEM vitamin and amino acid solutions (Sigma-Aldrich) to retain retinal viability. The perfusion solution was continuously bubbled with a $95 \% \mathrm{O}_{2} / 5 \% \mathrm{CO}_{2}$ mixture heated to $36-37^{\circ} \mathrm{C}$. The solution in the lower electrode compartment $(140 \mathrm{mM} \mathrm{NaCl}, 3.6 \mathrm{mM}$ $\mathrm{KCl}, 2.4 \mathrm{mM} \mathrm{MgCl}_{2}, 1.2 \mathrm{mM} \mathrm{CaCl}_{2}, 3$ mM HEPES, $10 \mathrm{mM}$ glucose, $\mathrm{pH} 7.4$ ) also contained $2 \mathrm{mM}$ L-glutamate and $10 \mathrm{mM} \mathrm{BaCl}_{2}$.

Light stimulation was applied as 20-ms test flashes of calibrated $505-\mathrm{nm}$ LED light. For light uniformity, a glass optical diffuser was placed between the LED and the retina. The stimulating light intensity was controlled by neutral density filters and a computer in $0.5 \log$ unit steps. Photoresponses were amplified by a differential amplifier (DP-311; Warner Instruments), low-pass filtered at $30 \mathrm{~Hz}$ (8-pole Bessel), digitized at $1 \mathrm{kHz}$, and stored in a computer for further analysis. The intensity-response relationships for both single-cell and transretinal recordings were fitted with Naka-Rushton hyperbolic functions, as follows:

$$
R=\frac{R_{\max } \times l^{n}}{l^{n}+l_{1 / 2}^{n}}
$$

(Equation 1)

for fitting absolute data, or

$$
\frac{R}{R_{\max }}=\frac{r^{n}}{r^{n}+r_{1 / 2}^{n}}
$$

(Equation 2)

for fitting normalized data - where $R$ is the transient-peak amplitude of response, $R_{\max }$ is the maximal response amplitude, $I$ is the flash intensity, $n$ is the Hill coefficient (exponent), and $I_{1 / 2}$ is the half-saturating light intensity.

Single-cell suction recordings. Three- to 5-week-old WT, EK and KK mice were dark-adapted overnight and sacrificed by $\mathrm{CO}_{2}$ asphyxiation, and their retinas were removed under infrared illumination, chopped into small pieces, and transferred to a perfusion chamber located on the stage of an inverted microscope. Then a single ROS was drawn into a glass microelectrode filled with a solution containing $140 \mathrm{mM} \mathrm{NaCl}, 3.6 \mathrm{mM} \mathrm{KCl}, 2.4 \mathrm{mM}$ 
$\mathrm{MgCl}_{2}, 1.2 \mathrm{mM} \mathrm{CaCl}_{2}, 3 \mathrm{mM}$ HEPES, pH 7.4, $0.02 \mathrm{mM}$ EDTA, and $10 \mathrm{mM}$ glucose. The perfusion Locke's solution (see previous section) was bubbled with a $95 \% \mathrm{O}_{2} / 5 \% \mathrm{CO}_{2}$ mixture and heated to $37-38^{\circ} \mathrm{C}$.

Light stimuli were applied in 20-ms test flashes of calibrated 500-nm light. Photoresponses were amplified, low-pass filtered $(30 \mathrm{~Hz}$, 8-pole Bessel), and digitized $(1 \mathrm{kHz})$. Normalized dim flash fractional sensitivity $\left(\mathrm{S}_{\mathrm{f}(\mathrm{n})}\right)$ was calculated from the linear region of the intensity-response curve as the ratio of the response amplitude to flash strength and then normalized by the amplitude of the saturating response. $\mathrm{I}_{1 / 2}$ was calculated from the intensity-response relationship as the test flash intensity required to produce a response with an amplitude equal to half of the corresponding saturated response amplitude. Integration time $\left(T_{\text {integr }}\right)$ was calculated as the integral of the dim flash response with the transient peak amplitude normalized to unity. The time constant for the dim flash response recovery $\left(\tau_{\text {rec }}\right)$ was derived from the best single-exponential fit to the declining phase of the response. The dominant recovery time constant $\left(\tau_{\mathrm{D}}\right)$ was determined from supersaturating flashes (70), by using a $10 \%$ criterion for photocurrent recovery from saturation. Data were analyzed with Clampfit 10.2 (Molecular Devices) and Origin 8.5 software (OriginLab).

Statistics. Data representing the mean \pm SEM (unless otherwise mentioned) are presented for the results of at least 3 independent experiments compared by 2 -tailed Student's $t$ test. Differences with $P$ values less than 0.05 were considered statistically significant.

Study approval. All animal procedures and experiments were approved by the CWRU and the Washington University Animal Care Committees and conformed to both the recommendations of the American Veterinary Medical Association Panel on Euthanasia and the Association of Research for Vision and Ophthalmology.

\section{Acknowledgments}

We thank M. Hitomi, T. Orban, H. Holdaway, and S. Roos (CWRU) for technical support. We also thank S. Sakami for technical advice. This work was supported by funding from the NIH (K08EY0190, K08EY019880, EY009339, EY 021126, EY019312, EY002687, P30 EY11373); a VAMC Career Development Grant; the Research to Prevent Blindness Foundation; Foundation Fighting Blindness; Fight for Sight; and the Ohio Lions Eye Research Foundation. D. Mustafi was supported in part by CWRU Medical Scientist Training Program Grant T32GM007250 and Visual Sciences Training Grant T32EY007157 from the NIH and the Maurice E. Müller Foundation of Switzerland. K. Palczewski is John H. Hord Professor of Pharmacology.

Received for publication August 3, 2012, and accepted in revised form October 4, 2012.

Address correspondence to: Krzysztof Palczewski, Department of Pharmacology, School of Medicine, Case Western Reserve University, 10900 Euclid Avenue, Cleveland, Ohio 44160, USA. Phone: 216.368.4631; Fax: 216.368.1300; E-mail: kxp65@case.edu.
1. Filipek S, Stenkamp RE, Teller DC, Palczewski K. G protein-coupled receptor rhodopsin: a prospectus. Annu Rev Physiol. 2003;65:851-879.

2. Palczewski K. Chemistry and biology of vision. J Biol Chem. 2012;287(3):1612-1619.

3. Palczewski K. G protein-coupled receptor rhodopsin. Annu Rev Biochem. 2006;75:743-767.

4. Kevany BM, Palczewski K. Phagocytosis of retinal rod and cone photoreceptors. Physiology. 2010; 25(1):8-15.

5. Hartong DT, Berson EL, Dryja TP. Retinitis pigmentosa. Lancet. 2006;368(9549):1795-1809.

6. Dykens JA, et al. Photoreceptor preservation in the S334ter model of retinitis pigmentosa by a novel estradiol analog. Biochem Pharmacol. 2004; 68(10):1971-1984.

7. Mao H, Gorbatyuk MS, Rossmiller B, Hauswirth WW, Lewin AS. Long-term rescue of retinal structure and function by rhodopsin RNA replacement with a single adeno-associated viral vector in $\mathrm{P} 23 \mathrm{H}$ RHO transgenic mice. Hum Gene Ther. 2012;23(4):356-366.

8. Farrar GJ, Palfi A, O’Reilly M. Gene therapeutic approaches for dominant retinopathies. Curr Gene Ther. 2010;10(5):381-388.

9. Smith AJ, Bainbridge JW, Ali RR. Prospects for retinal gene replacement therapy. Trends Genet. 2009;25(4):156-165.

10. Drack AV, et al. TUDCA slows retinal degeneration in two different mouse models of retinitis pigmentosa and prevents obesity in Bardet-Biedl syndrome type 1 mice. Invest Ophthalmol Vis Sci. 2012; 53(1):100-106.

11. Nathans J. Rhodopsin: structure, function, and genetics. Biochemistry. 1992;31(21):4923-4931.

12. Hollingsworth TJ, Gross AK. Defective trafficking of rhodopsin and its role in retinal degenerations. Int Rev Cell Mol Biol. 2012;293:1-44.

13. Malanson KM, Lem J. Rhodopsin-mediated retinitis pigmentosa. Prog Mol Biol Transl Sci. 2009;88:1-31.

14. Rosenfeld PJ, Cowley GS, McGee TL, Sandberg MA, Berson EL, Dryja TP. A null mutation in the rhodopsin gene causes rod photoreceptor dysfunction and autosomal recessive retinitis pigmentosa. Nat Genet. 1992;1(3):209-213.
15. Kumaramanickavel G, et al. Missense rhodopsin mutation in a family with recessive RP. Nat Genet. 1994;8(1):10-11.

16. Azam M, et al. A homozygous p.Glu150Lys mutation in the opsin gene of two Pakistani families with autosomal recessive retinitis pigmentosa. $\mathrm{Mol}$ Vis. 2009; 15:2526-2534.

17. Pulagam LP, Palczewski K. Electrostatic compensation restores trafficking of the autosomal recessive retinitis pigmentosa $\mathrm{E} 150 \mathrm{~K}$ opsin mutant to the plasma membrane. J Biol Chem. 2010; 285(38):29446-29456.

18. Zhu L, et al. Autosomal recessive retinitis pigmentosa and E150K mutation in the opsin gene. J Biol Chem. 2006;281(31):22289-22298.

19. Liang Y, et al. Rhodopsin signaling and organization in heterozygote rhodopsin knockout mice. J Biol Chem. 2004;279(46):48189-48196.

20. Wen XH, et al. Overexpression of rhodopsin alters the structure and photoresponse of rod photoreceptors. Biophys J. 2009;96(3):939-950.

21. Lem J, et al. Morphological, physiological, and biochemical changes in rhodopsin knockout mice. Proc Natl Acad Sci U S A. 1999;96(2):736-741.

22. Humphries MM, et al. Retinopathy induced in mice by targeted disruption of the rhodopsin gene. Nat Genet. 1997;15(2):216-219.

23. Liang Y, Fotiadis D, Filipek S, Saperstein DA, Palczewski K, Engel A. Organization of the G proteincoupled receptors rhodopsin and opsin in native membranes. J Biol Chem. 2003;278(24):21655-21662.

24. Fotiadis D, Liang Y, Filipek S, Saperstein DA, Engel A, Palczewski K. Atomic-force microscopy: rhodopsin dimers in native disc membranes. Nature. 2003;421(6919):127-128.

25. Fotiadis D, Liang Y, Filipek S, Saperstein DA, Engel A, Palczewski K. The G protein-coupled receptor rhodopsin in the native membrane. FEBS Lett. 2004;564(3):281-288.

26. Palczewski K, et al. Crystal structure of rhodopsin: a G protein-coupled receptor. Science. 2000; 289(5480):739-745.

27. Jastrzebska B, et al. Expression of mammalian G protein-coupled receptors in Caenorhabditis elegans.
Methods Enzymol. In press.

28. Jastrzebska B, Tsybovsky Y, Palczewski K. Complexes between photoactivated rhodopsin and transducin: progress and questions. Biochem J. 2010;428(1):1-10.

29. Sakami S, et al. Probing mechanisms of photoreceptor degeneration in a new mouse model of the common form of autosomal dominant retinitis pigmentosa due to $\mathrm{P} 23 \mathrm{H}$ opsin mutations. J Biol Chem. 2011;286(12):10551-10567.

30. Okada T, Le Trong I, Fox BA, Behnke CA, Stenkamp RE, Palczewski K. X-Ray diffraction analysis of three-dimensional crystals of bovine rhodopsin obtained from mixed micelles. J Struct Biol. 2000;130(1):73-80.

31. Li ZY, Kljavin IJ, Milam AH. Rod photoreceptor neurite sprouting in retinitis pigmentosa. J Neurosci. 1995;15(8):5429-5438.

32. Busskamp V, et al. Genetic reactivation of cone photoreceptors restores visual responses in retinitis pigmentosa. Science. 2010;329(5990):413-417.

33. Kolesnikov AV, Kefalov VJ. Transretinal ERG recordings from mouse retina: rod and cone photoresponses. J Vis Exp. 2012;(61):3424.

34. Krispel CM, et al. RGS expression rate-limits recovery of rod photoresponses. Neuron. 2006;51(4):409-416.

35. Hao W, et al. Evidence for two apoptotic pathways in light-induced retinal degeneration. Nat Genet. 2002;32(2):254-260.

36. Denk W, Horstmann H. Serial block-face scanning electron microscopy to reconstruct threedimensional tissue nanostructure. PLoS Biol. 2004; 2(11):e329.

37. Mustafi D, et al. Defective photoreceptor phagocytosis in a mouse model of enhanced S-cone syndrome causes progressive retinal degeneration. FASEB J. 2011;25(9):3157-3176.

38. Oprian DD, Molday RS, Kaufman RJ, Khorana HG. Expression of a synthetic bovine rhodopsin gene in monkey kidney cells. Proc Natl Acad Sci U S A. 1987;84(24):8874-8878.

39. Maeda A, et al. Palmitoylation stabilizes unliganded rod opsin. Proc Natl Acad Sci U S A. 2010; 107(18):8428-8433.

40. Mustafi D, Maeda T, Kohno H, Nadeau JH, Palc- 
zewski K. Inflammatory priming predisposes mice to age-related retinal degeneration. J Clin Invest. 2012;122(8):2989-3001.

41. Jacque CM, Vinner C, Kujas M, Raoul M, Racadot J, Baumann NA. Determination of glial fibrillary acidic protein (GFAP) in human brain tumors. J Neurol Sci. 1978;35(1):147-155.

42. Roessmann U, Velasco ME, Sindely SD, Gambetti P. Glial fibrillary acidic protein (GFAP) in ependymal cells during development. An immunocytochemical study. Brain Res. 1980;200(1):13-21.

43. Imai Y, Kohsaka S. Intracellular signaling in M-CSF-induced microglia activation: role of Iba1. Glia. 2002;40(2):164-174.

44. Batten ML, et al. Lecithin-retinol acyltransferase is essential for accumulation of all-trans-retinyl esters in the eye and in the liver. J Biol Chem. 2004; 279(11):10422-10432.

45. Fan J, Rohrer B, Frederick JM, Baehr W, Crouch RK. Rpe $65^{-/-}$and Lrat $^{-/-}$mice: comparable models of leber congenital amaurosis. Invest Ophthalmol Vis Sci. 2008;49(6):2384-2389.

46. Woodruff ML, Wang Z, Chung HY, Redmond TM, Fain GL, Lem J. Spontaneous activity of opsin apoprotein is a cause of Leber congenital amaurosis. Nat Genet. 2003;35(2):158-164.

47. Neveling K, et al. Next-generation genetic testing for retinitis pigmentosa. Hum Mutat. 2012;33(6):963-972.

48. Dryja TP. Molecular genetics of Oguchi disease, fundus albipunctatus, and other forms of stationary night blindness: LVII Edward Jackson Memorial Lecture. Am J Ophthalmol. 2000;130(5):547-563.

49. De Laey JJ. Flecked retina disorders. Bull Soc Belge Ophtalmol. 1993;249:11-22.

50. Travis GH, Golczak M, Moise AR, Palczewski K. Diseases caused by defects in the visual cycle: retinoids as potential therapeutic agents. Annu Rev Pharmacol Toxicol. 2007;47:469-512.

51. Kiser PD, Golczak M, Maeda A, Palczewski K.
Key enzymes of the retinoid (visual) cycle in vertebrate retina. Biochimica et Biophysica Acta. 2012; 1821(1):137-151.

52. von Lintig J, Kiser PD, Golczak M, Palczewski K. The biochemical and structural basis for trans-tocis isomerization of retinoids in the chemistry of vision. Trends Biochem Sci. 2010;35(7):400-410.

53. Zhu L, et al. A naturally occurring mutation of the opsin gene (T4R) in dogs affects glycosylation and stability of the $\mathrm{G}$ protein-coupled receptor. J Biol Chem. 2004;279(51):53828-53839.

54. Calvert PD, et al. Phototransduction in transgenic mice after targeted deletion of the rod transducin alpha -subunit. Proc Natl Acad Sci U S A. 2000; 97(25):13913-13918.

55. Batten ML, et al. Pharmacological and rAAV gene therapy rescue of visual functions in a blind mouse model of Leber congenital amaurosis. PLoS Med. 2005;2(11):e333.

56. Pittler SJ, Baehr W. Identification of a nonsense mutation in the rod photoreceptor cGMP phosphodiesterase beta-subunit gene of the rd mouse. Proc Natl Acad Sci U S A. 1991;88(19):8322-8326.

57. Mehalow AK, et al. CRB1 is essential for external limiting membrane integrity and photoreceptor morphogenesis in the mammalian retina. Hum Mol Genet. 2003;12(17):2179-2189.

58. MacKenzie D, Arendt A, Hargrave P, McDowell JH, Molday RS. Localization of binding sites for carboxyl terminal specific anti-rhodopsin monoclonal antibodies using synthetic peptides. Biochemistry. 1984;23(26):6544-6549.

59. Adamus G, Zam ZS, Arendt A, Palczewski K, McDowell JH, Hargrave PA. Anti-rhodopsin monoclonal antibodies of defined specificity: characterization and application. Vision Res. 1991;31(1):17-31.

60. Zhu Q, et al. Sponge transgenic mouse model reveals important roles for the microRNA-183 (miR183)/96/182 cluster in postmitotic photoreceptors of the retina. J Biol Chem. 2011;286(36):31749-31760.

61. Zhang T, Zhang N, Baehr W, Fu Y. Cone opsin determines the time course of cone photoreceptor degeneration in Leber congenital amaurosis. Proc Natl Acad Sci U S A. 2011;108(21):8879-8884.

62. Fiala JC. Reconstruct: a free editor for serial section microscopy. J Microsc. 2005;218(pt 1):52-61.

63. Matthews RG, Hubbard R, Brown PK, Wald G. Tautomeric forms of metarhodopsin. J Gen Physiol. 1963;47:215-240.

64. Farrens DL, Khorana HG. Structure and function in rhodopsin. Measurement of the rate of metarhodopsin II decay by fluorescence spectroscopy. J Biol Chem. 1995;270(10):5073-5076.

65. Farrens DL, Altenbach C, Yang K, Hubbell WL, Khorana HG. Requirement of rigid-body motion of transmembrane helices for light activation of rhodopsin. Science. 1996;274(5288):768-770.

66 . Heck M, et al. Signaling states of rhodopsin. Formation of the storage form, metarhodopsin III, from active metarhodopsin II. J Biol Chem. 2003; 278(5):3162-3169.

67. Maeda A, et al. Role of photoreceptor-specific retinol dehydrogenase in the retinoid cycle in vivo. J Biol Chem. 2005;280(19):18822-18832.

68. Sillman AJ, Ito H, Tomita T. Studies on the mass receptor potential of the isolated frog retina. I. General properties of the response. Vision Res. 1969; 9(12):1435-1442.

69. Nymark S, Heikkinen H, Haldin C, Donner K, Koskelainen A. Light responses and light adaptation in rat retinal rods at different temperatures. J Physiol. 2005;567(pt 3):923-938.

70. Pepperberg DR, et al. Light-dependent delay in the falling phase of the retinal rod photoresponse. Vis Neurosci. 1992;8(1):9-18.

71. Jastrzebska B, et al. Rhodopsin-transducin heteropentamer: three-dimensional structure and biochemical characterization. J Struc Biol. 2011;176(3):387-394. 